\title{
Sex-dependent compensatory mechanisms preserve blood pressure homeostasis in prostacyclin receptor- deficient mice
}

\author{
Soon Y. Tang, ${ }^{1}$ Hu Meng, ${ }^{1}$ Seán T. Anderson, ${ }^{1}$ Dimitra Sarantopoulou, ${ }^{1}$ Soumita Chosh, ${ }^{1}$ Nicholas F. Lahens, ${ }^{1}$ \\ Katherine N. Theken, ${ }^{1}$ Emanuela Ricciotti, ${ }^{1}$ Elizabeth J. Hennessy, ${ }^{1}$ Vincent Tu, ${ }^{2}$ Kyle Bittinger, ${ }^{2}$ Aalim M. Weiljie, ${ }^{1}$ \\ Gregory R. Grant, ${ }^{1,3}$ and Garret A. FitzGerald ${ }^{1}$
}

IInstitute for Translational Medicine and Therapeutics, Department of Systems Pharmacology and Translational Therapeutics, Perelman School of Medicine, University of Pennsylvania, Philadelphia, Pennsylvania, USA. Division of Gastroenterology, Hepatology, and Nutrition, Children's Hospital of Philadelphia, Philadelphia, Pennsylvania, USA. ${ }^{3}$ Department of Cenetics, University of Pennsylvania, Philadelphia, Pennsylvania, USA.

Inhibitors of microsomal prostaglandin E synthase 1 (mPGES-1) are in the early phase of clinical development. Deletion of mPges-1 in mice confers analgesia, restrains atherogenesis, and fails to accelerate thrombogenesis, while suppressing prostaglandin $E_{2}\left(P C E_{2}\right)$, but increasing the biosynthesis of prostacyclin $\left(P \mathrm{PI}_{2}\right)$. In low-density lipoprotein receptor-deficient $\left(\right.$ LdIr $\left.^{-/}\right)$mice, this last effect represents the dominant mechanism by which $\mathrm{mPges}-1$ deletion restrains thrombogenesis, while suppression of $\mathrm{PCE}_{2}$ accounts for its antiatherogenic effect. However, the effect of $\mathrm{mPges}-1$ depletion on blood pressure (BP) in this setting remains unknown. Here, we show that mPges-1 depletion significantly increased the BP response to salt loading in male $\mathrm{LdI}^{-1-}$ mice, whereas, despite the direct vasodilator properties of $\mathrm{PCI}_{2}$, deletion of the I prostanoid receptor (Ipr) suppressed this response. Furthermore, combined deletion of the Ipr abrogated the exaggerated BP response in male mPges-1/-- mice. Interestingly, these unexpected BP phenotypes were not observed in female mice fed a high-salt diet (HSD).

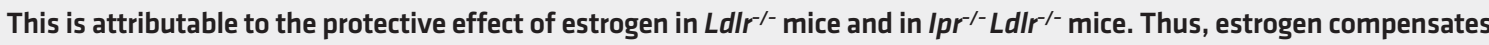
for a deficiency in $\mathrm{PGI}_{2}$ to maintain $\mathrm{BP}$ homeostasis in response to high salt in hyperlipidemic female mice. In male mice, by contrast, the augmented formation of atrial natriuretic peptide (ANP) plays a similar compensatory role, restraining hypertension and oxidant stress in the setting of Ipr depletion. Hence, men with hyperlipidemia on a HSD might be at risk of a hypertensive response to $\mathrm{mPCES}-1$ inhibitors.

\section{Introduction}

Both the adverse cardiovascular events associated with nonsteroidal antiinflammatory drugs (NSAIDs) and the opioid crisis have prompted interest in developing new analgesics (1-4). Several clinical trials have shown that the incidence and severity of hypertension from NSAID use are quite variable in humans (5-8). Inhibitors of microsomal prostaglandin synthase 1 (mPGES-1), an enzyme involved in the biosynthesis of prostaglandin $\mathrm{E}_{2}\left(\mathrm{PGE}_{2}\right)$, are in early clinical development as potential nonaddictive analgesics devoid of the cardiovascular hazards attributable to inhibition of COX-2 by NSAIDs.

Deletion of mPges- 1 has a mild adverse cardiovascular profile in normolipidemic mice (3), and we have reported that rediversion of the mPGES-1 substrate prostaglandin $\mathrm{H}_{2}\left(\mathrm{PGH}_{2}\right)$ to prostacyclin $\left(\mathrm{PGI}_{2}\right.$ ) synthase, augmenting $\mathrm{PGI}_{2}$, attenuates thrombogenesis in hyperlipidemic mice (9). This is a point of distinction from COX-2 depletion or inhibition that suppresses the synthesis of this endogenous platelet inhibitor and predisposes mice to thrombogenic stimuli (3).

Conflict of interest: The authors have declared that no conflict of interest exists. Copyright: () 2021, American Society for Clinical Investigation.

Submitted: January 10, 2020; Accepted: June 3, 2021; Published: July 15, 2021

Reference information: J Clin Invest. 2021;131(14):e136310.

https://doi.org/10.1172/JCl136310.
Sexual dimorphism in blood pressure (BP) homeostasis is at least partly explained by the endocrine system. For example, systolic blood pressure (SBP) is higher in boys from 13 years of age on compared with girls of the same age (10), and the hypertensive response to salt loading is more pronounced in apparently healthy men compared with premenopausal women at different ages (11). Similarly, in genetically and experimentally predisposed rodent models, hypertension develops more slowly in female mice than in male mice $(12,13)$. Deletion of the $\mathrm{PGE}_{2}$ receptor Epr1 reduced $\mathrm{BP}$ in male, but not female, mice (14). Besides, BP homeostasis is also closely linked to the immune system, inflammation, and the composition of gut microbiota (15-17). In both human and rodent studies, a high-salt diet (HSD) has been shown to increase BP while decreasing the $\alpha$ - and $\beta$-diversity of the microbiome (18). Among others, the Lactobacillus species has a negative association with $\mathrm{BP}$ responses (19).

Here, the BP response to a HSD was augmented in hyperlipidemic mice lacking the low-density lipoprotein receptor (Ldlr, referred to herein as $\mathrm{Ldll}^{-/}$mice). Both $\mathrm{PGE}_{2}$ and $\mathrm{PGI}_{2}$ may act as direct vasodilators, so we assumed that exaggeration of this response in mPges-1-deficient mice was attributable to the suppression of $\mathrm{PGE}_{2}$, despite augmented formation of $\mathrm{PGI}_{2}$ in these mice. To our surprise, deletion of the I pros- 




$$
\begin{aligned}
& \text { mPges - } 1^{-1-L d l r^{-1}}(n=13) \\
& \mid p r^{-/} \text {mPges-1 } 1^{--} \text {Ldl }^{-}(n=15) \\
& \text { B }
\end{aligned}
$$

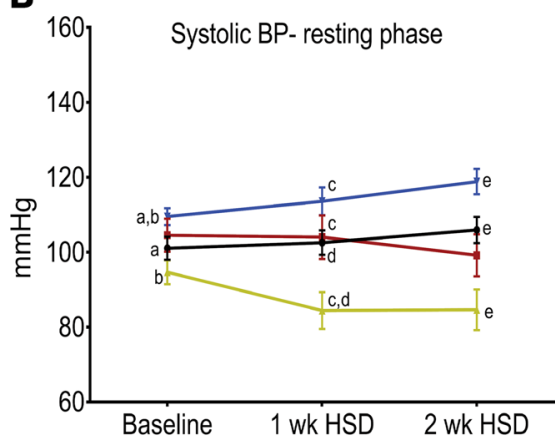

C

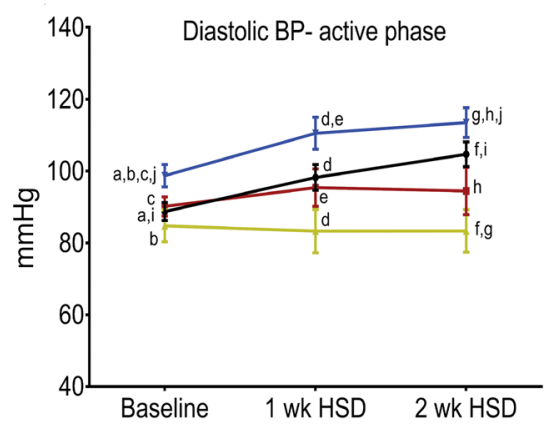

D

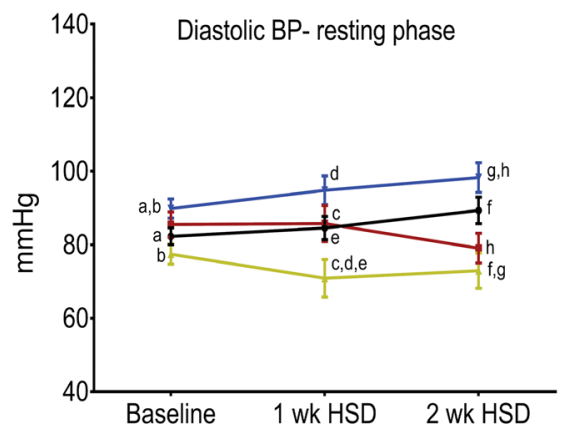

Figure 1. Ipr deletion in mPges-1-deficient male hyperlipidemic mice abrogates salt-evoked hypertension. (A and B) SBP in male hyperlipidemic mice and mutants fed a HSD was measured via telemetry. A HSD led to a rise in SBP in Ldlr ${ }^{-1-}($ Ldlr-KO) mice in a time-dependent pattern, during both the active (night) and resting (day) periods. Deletion of mPges-1 in Ldlr ${ }^{-1-}$ mice augmented salt-evoked hypertension. By contrast, deletion of the Ipr restrained salt-evoked hypertension and abrogated the hypertensive phenotype in $\mathrm{Ipr}^{-/-} \mathrm{mPges}-\mathrm{1}^{-/} \mathrm{Ldll}^{-/-}$mutant mice. A 4-way, repeatedmeasures ANOVA showed a significant effect of the Ipr, mPges-1, phase, and a few of the 2- and 4-way interactions (Ipr:week, week:phase, Ipr:mPges-1:week:phase) on SBP. A post hoc pairwise $t$ test showed a significant effect on SBP in week 2 with respect to baseline SBP for $\mathrm{Ldll}^{-1-}$ mice. (C and D) Similar trends in DBP responses were observed in both the active and resting periods in all mutant mice and their littermate controls fed a HSD. A 4-way, repeated-measures ANOVA showed a significant effect of the Ipr, week, phase, and week:phase interaction on DBP. A pairwise $t$ test showed a significant effect on DBP only by week 2 compared with baseline DPB for $\mathrm{Ldll}^{-1-}$ mice. A

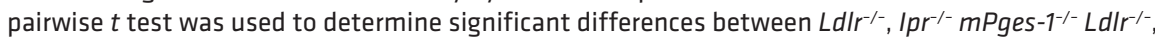
$\mid \mathrm{pr}^{-1-} \mathrm{Ldll}^{-/-}$(double-KO [DKO]), and $\mathrm{mPges} \mathrm{T}^{-1-}$ Ldlr $^{-1-}$ mice. Genotypes and feeding periods with the same lowercase letter were significantly different $(a-j, P<0.05)$ at baseline, 1 week on a HSD, or 2 weeks on a HSD. For example, a - the baseline SBP (active phase) of mPges-1/- Ldlr-1- (DKO) mice was significantly elevated compared with that of $L d l r^{-1-}$ mice and $b-I p r^{-1-} L d l r^{-1-}$ mice; $f$ - the SBP (active phase) of mPges-1-/- Ldlr ${ }^{-1-}$ mice was significantly elevated after 2 weeks on a HSD compared with baseline SBP. Data are expressed as the mean \pm SEM. $n=13-16$ mice per genotype.

tanoid receptor (Ipr) attenuated the hypertensive response to mPges-1 deletion. Furthermore, we observed this in male, but not female, mice. Mechanistically, we found that Ipr deletion resulted in release of the vasodilator atrial natriuretic peptide (ANP) $(20,21)$ and attenuation of the oxidant stress that characterizes hyperlipidemia (22) in male mice. This resulted in abrogation of the hypertensive response to salt. In female mice, by contrast, we did not observe these responses, whereas in ovariectomized (OVX) mice, estrogen attenuated salt-evoked hypertension in both $\mathrm{Ldlr}^{-/}$and $\mathrm{Ipr}^{-/} \mathrm{Ldlr}^{-/}$mice, but not in mPges-1-1- $\mathrm{Ldlr}^{-/}$mice. A HSD markedly reduced the abundance of Lactobacillus only in male mice, coinciding with a reduction in their fecal product indole-3-lactic acid. A reduction of this metab- olomics restraint on inflammation and oxidative stress may have contributed to the sexually dimorphic, exaggerated saltinduced hypertension that we observed.

\section{Results}

Deletion of the Ipr in mPges-1-deficient hyperlipidemic mice abrogates salt-evoked hypertension. Hyperlipidemic mice $\left(L d l r^{--}\right)$were used in the current study to simulate more closely the atherosclerosis likely extant in elderly patients targeted for analgesia with mPGES-1 inhibitors. As shown in Supplemental Figure 1, A-D (supplemental material available online with this article; https://doi.org/10.1172/JCI136310DS1), despite being fed a chow diet, plasma cholesterol and/or triglyceride levels of $\mathrm{Ldlr}^{-/}$ and Ipr-and mPges-1-deficient $\mathrm{Ldlr}^{-/}$mice were significantly elevated.

Male $\mathrm{Ldlr}^{--}$mice fed a HSD showed a time-dependent elevation of SBP in the active (night) period (Figure 1, A and B). The SBP was significantly elevated in week 2 compared with baseline during the active phase. Deletion of mPges-1 led to a further significant increase in the salt-evoked BP response. By contrast, deletion of the Ipr unexpectedly restrained the hypertensive response to the HSD in both $\mathrm{Ldlr}^{-1-}$ mice and those also lacking mPges-1. At baseline, male mice lacking both mPges-1 and the Ldlr had elevated BPs compared with BPs of mice of the other genotypes (Figure 1). Thereafter, the attenuating effects of Ipr deletion became apparent: the SBPs of $\mathrm{Ldlr}^{-/}$, mPges-1/- $\mathrm{Ldlr}^{-/}$, and $\mathrm{Ipr}^{-1} \mathrm{mPges}-\mathrm{1}^{-/-} \mathrm{Ldlr}^{-/}$mice were significantly elevated compared with SBPs of $\mathrm{Ipr}^{-1-} \mathrm{Ldlr}^{-/}$mice 1 week and/or 2 weeks after they were fed a HSD. We observed similar differences in diastolic blood pressure (DBP) responses in all mutants and their littermate controls fed a HSD during the active and resting periods (Figure 1, C and D). The DBPs in $\mathrm{Ldlr}^{-/}$mice were significantly elevated in week 2 compared with baseline DBPs during the active phase. Compared with $\mathrm{Ipr}^{-/} \mathrm{Ldlr}^{-/}$ mice, the DBPs of $\mathrm{Ldlr}^{-/}$, mPges-1-/- $\mathrm{Ldlr}^{-/}$, and $\mathrm{Ipr}^{-/} \mathrm{mPges}-\mathrm{1}^{-/-} \mathrm{Ldlr}$ /- mice were significantly elevated at baseline as well as 1 week and/or 2 weeks after HSD feeding. However, we did not observe these HSD-evoked BP responses in female hyperlipidemic mice (Supplemental Figure 2, A-D). In addition, weight gain, the urinary output/fluid intake ratio, and urinary sodium levels did not appear to explain the sex differences in $\mathrm{BP}$ responses to the salt loading in our mice (Supplemental Figure 3, A-C). We were not able to accurately measure food intake in the current study, because the HSD was very hygroscopic. 

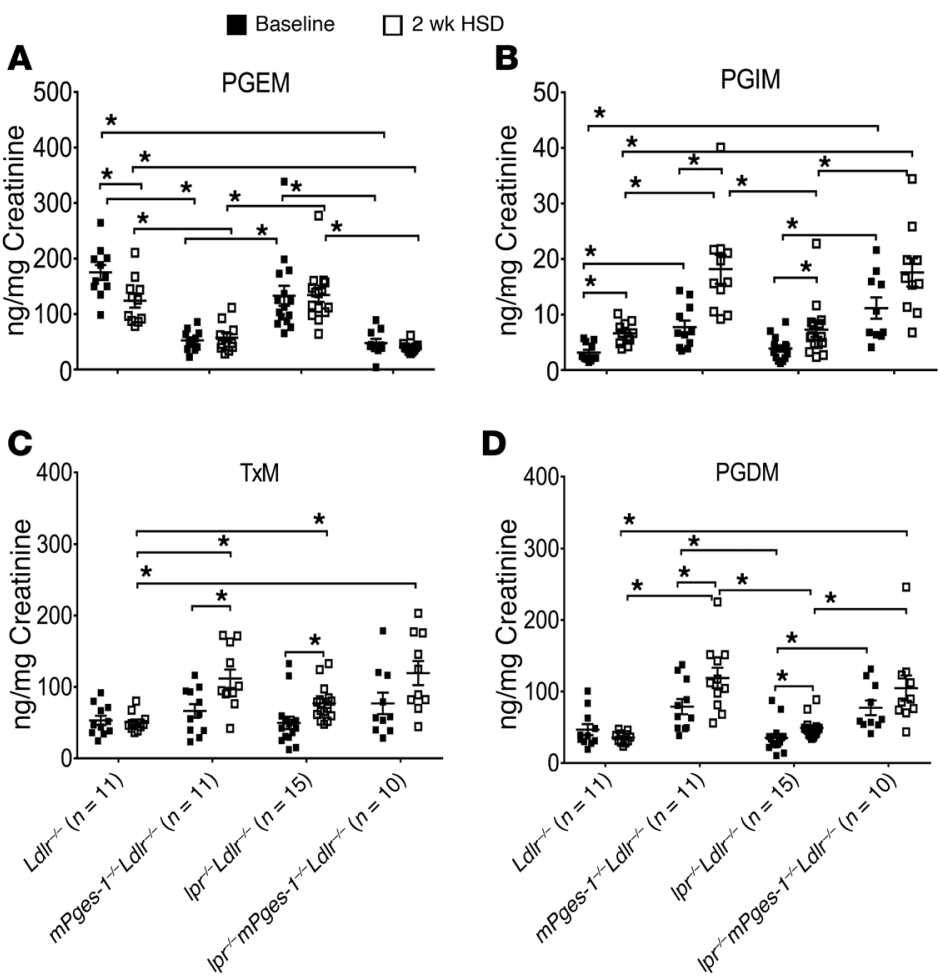

Figure 2. Impact of Ipr and mPges-1 deletion on prostaglandin biosynthesis in male hyperlipidemic mice on a HSD. Fasting ( 9 am- 4 pm) urine samples


collected before and 2 weeks after HSD feeding, and prostanoid metabolites were analyzed by LC-MS/MS, as described in Methods. LdIr-- mice fed a HSD showed suppressed $\mathrm{PGE}_{2}$ but increased $\mathrm{PGI}_{2}$ biosynthesis as reflected in their urinary (A) PGEM and (B) PGIM metabolites, respectively. Deletion of mPges-1 suppressed $\mathrm{PGE}_{2}$ but increased $\mathrm{PGI}_{2}$ biosynthesis in $\mathrm{mPges} \mathrm{-1}^{-/-} \mathrm{Ldlr}^{-/}$and $\mathrm{Irr}^{-/-} \mathrm{mPges}^{-1^{-/-}}$ $\mathrm{LdIr}^{-1-}$ mice. Deletion of the Ipr did not alter PGEM or PGIM levels at baseline but increased PCIM levels on the HSD. (C) HSD feeding also increased urinary 2,3-dinor $\mathrm{TxB}_{2}$ (TxM) levels in DKO mutant mice. (D) After HSD feeding, urinary PGDM (11,15-dioxo-9 $\alpha$-hydroxy-2,3,4,5-tetranorprostan-1,20-dioic acid) levels were significantly elevated in $\mathrm{mPges}-\mathrm{1}^{-1-} \mathrm{Ldll}^{-/}$and $\mathrm{Ipr}^{-1-} \mathrm{Ldll}^{-/-}$mice. A 3-way ANOVA showed that urinary PGIM, PGDM, and TXM levels were significantly affected by mPges-1 deletion when mice were fed a HSD. PGEM interacted significantly alone and together with Ipr status and whether the mice were on a HSD. Pairwise $t$ tests



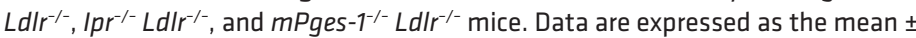
SEM. ${ }^{*} P<0.05 . n=10-15$ mice per genotype.

Detailed statistical analyses of the interactions among genotypes, treatment (week), and phases for both sexes are described in the Supplemental Methods.

Impact of Ipr and mPges-1 deletion on prostaglandin biosynthesis in male hyperlipidemic mice on a HSD. Two weeks of HSD feeding suppressed $\mathrm{PGE}_{2}$ but increased $\mathrm{PGI}_{2}$ biosynthesis in male $\mathrm{Ldlr}^{-}$mice, as reflected in their urinary PGEM (7-hydroxy-5, 11-diketotetranorprostane-1, 16-dioic acid) and PGIM (2, 3-dinor 6-keto PGF $_{10}$ ) metabolites, respectively (Figure 2, A and B). Overall (Figure 2), deletion of mPges-1 in the hyperlipidemic mice (mPges-1-/ $\left.\mathrm{Ldlr}^{-}\right)$) suppressed $\mathrm{PGE}_{2}$ and augmented the formation of $\mathrm{PGI}_{2}$, thromboxane $\mathrm{B}_{2}\left(\mathrm{TxB}_{2}\right)$ (Figure $2 \mathrm{C}$ ), and $\mathrm{PGD}_{2}$ (Figure 2D), as expected consequent to substrate rediversion. These changes were more pronounced in mice on the HSD. Finally, deletion of the Ipr resulted in a reactive increase in the biosynthesis of $\mathrm{PGI}_{2}$, but also of $\mathrm{TxB}_{2}$ and $\mathrm{PGD}_{2}$, again apparent on a HSD.

Detailed statistical analyses of the interactions among urinary prostaglandin metabolites, mouse genotypes, and treatment (week) are described in the Supplemental Methods.

Pharmacological inhibition of the human MPGES-1 enzyme elevates SBP in hyperlipidemic male mice. To confirm the hypertensive phenotype of global $\mathrm{mPges}^{-1^{-/}} \mathrm{Ldlr}^{-1}$ mice, we administered the mPGES- 1 inhibitor MF970 $(10 \mathrm{mg} / \mathrm{kg}$ BW) concomitantly with a high-fat diet (HFD) for 39 weeks to humanized mPGES-1 $\mathrm{Ldlr}^{-}$male mice. As shown in Supplemental Figure 4, inhibition of mPGES-1 suppressed urinary PGEM (Supplemental Figure 4A) and increased the SBP response (Supplemental Figure 4B) as compared with control mice on a HFD alone.

A HSD activates ANP synthesis and release in Ipr-deficient mice. The unexpected suppression of the salt-evoked elevation of BP by Ipr deletion prompted us to compare gene expression profiles in the renal medullae of male $\mathrm{Ldlr}^{--}$and $\mathrm{Ipr}^{-1} \mathrm{Ldlr}^{-1}$ mice by high-throughput RNA-Seq. We identified 2719 differentially expressed genes (DEGs), with a log fold change ranging from 2.64 to -3.83 between $\mathrm{Ldlr}^{-}$ and $\mathrm{Ipr}^{-} \mathrm{Ldlr^{- } -}$ mice at a FDR cutoff of 0.12. One thousand ninety-seven of these 2719 DEGs were upregulated, and 1622 were downregulated in the renal medulla of $\mathrm{Ipr}^{-1}$

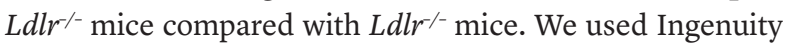
Pathway Analysis to assess changes in biological pathways associated with gene expression (Table 1), and the pathways most enriched with DEGs included eukaryotic initiation factor 2 (eIF2), eIF4/p70S6K signaling, mitochondrial dysfunction, and oxidative phosphorylation. Sixty-three of the 76 identified genes in the eIF2 pathway were downregulated in the $\mathrm{Ipr}^{-} \mathrm{Ldlr} /$ mice and were mostly members of the 60s and 40s ribosomal subunits involved in RNA binding (Figure 3A and Supplemental Table 1). Forty-five of 47 genes related to mitochondrial dysfunction and oxidative phosphorylation were downregulated in the $\mathrm{Ipr}^{-1} \mathrm{Ldlr}^{-1}$ mice (Figure 3A and Supplemental Table 1). Most of these genes are components of mitochondrial complexes $\mathrm{I}-\mathrm{V}$, which are involved in electron transport and ATP synthesis. We validated 3 of the genes (downregulated: Atp5e, a subunit of mitochondrial ATP synthase; upregulated: Cat and Sod2, which are antioxidant enzymes) in the mitochondrial dysfunction and oxidative phosphorylation pathways by reverse transcription quantitative PCR (RT-qPCR) (Supplemental Figure 5, A and B). In addition, the RNA-Seq data were consistent with activation of the ANP pathway. We found that expression of neprilysin (Mme), which degrades natriuretic peptides, was elevated in $\mathrm{Ipr}^{-} \mathrm{Ldlr}^{-}$ mice compared with expression levels in $\mathrm{Ldll}^{\circ} /$ mice (Figure 3B). We confirmed by RT-qPCR that mRNA levels of corin (ANPconverting enzyme) and $A N P$, but not brain natriuretic peptide $(B N P)$, were significantly increased in whole-heart lysates from $\mathrm{Ipr}^{-} \mathrm{Ldll}^{-1}$ mice (Figure 3, C-E). Moreover, renal medullary mRNA expression of Npr1, a receptor of ANP, was significantly increased (Figure 3F). Consistent with the gene expression data, urinary ANP levels were also elevated in $\mathrm{Ipr}^{-/} \mathrm{Ldll} \mathrm{r}^{-/}$mice compared with levels 


\section{Table 1. Top canonical pathways predicted by Ingenuity Pathway Analysis for the 2719 DEGs in kidney medulla between male LdIr $r^{-/}$and $I p r^{-/-}$LdIr $^{-/-}$mice on a HSD}

\begin{tabular}{lcc} 
Canonical pathway & $\boldsymbol{P}$ value & Overlap \\
elF2 signaling & $8.27 \times 10^{-21}$ & $76 / 194$ \\
\hline Oxidative phosphorylation & $2.62 \times 10^{-17}$ & $47 / 99$ \\
\hline Mitochondrial dysfunction & $8.26 \times 10^{-16}$ & $60 / 159$ \\
\hline Regulation of elF4 and p70S6K signaling & $4.06 \times 10^{-8}$ & $47 / 164$
\end{tabular}

Seventy-six of the 194 genes associated with the elF2 signaling pathway were differentially expressed in $I p r^{-1-} L_{d l l} r^{-1}$ mice compared with $L d l r^{-1-}$ mice.

in $\mathrm{Ldlr}^{-/}$mice after 2 weeks on the HSD (Figure 4, A and B). We did not observe a significant difference in creatinine levels in the urine samples between $\mathrm{Ldlr}^{-/}$and $\mathrm{Ipr}^{-/} \mathrm{Ldlr}^{-/}$mutants (Supplemental Figure 3D). Thus, elevated urinary ANP levels were not likely to be confounded by differences in fluid intake. Consistent with the role of $\mathrm{PGI}_{2}$ in restraining oxidative stress in atherosclerotic vasculature (23) and in salt-induced hypertension $(24,25)$ and the elevation of $\mathrm{PGI}_{2}$ biosynthesis in mice on the HSD (Figure 2), excretion of a major urinary $\mathrm{F}_{2}$-isoprostane $\left(\mathrm{F}_{2} \mathrm{iP}\right)$, an index of lipid peroxidation, was not significantly elevated in $\mathrm{Ldlr}^{-/}$mice after 2 weeks on a HSD (Figure 4, C and D). However, rather than increase with Ipr deletion, $\mathrm{F}_{2} \mathrm{iP}$ excretion, just like $\mathrm{BP}$, unexpectedly fell, consistent with the changes in mitochondrial dysfunction and oxidative phosphorylation genes observed in the renal medulla of $\mathrm{Ipr}^{-/} \mathrm{Ldlr}^{-1}$ mice (mostly downregulated in the $\mathrm{Ipr}^{-/} \mathrm{Ldlr}^{-/}$mice; Figure 4D). The reduction in urinary $\mathrm{F}_{2} \mathrm{iP}$ and elevated ANP levels consequent to Ipr deletion in the $\mathrm{Ldlr}^{-/}$mice was abrogated by treatment with the ANP receptor antagonist A71915 (refs. 26-28 and Figure 4, E and F). This is consistent with evidence that ANP is both a vasodilator and a restraint on oxidative stress $(27,29)$.

The hypotensive phenotype of $\mathrm{Ipr}^{-/} \mathrm{Ldlr}^{-/}$mice was not associated with gross morphological changes in the kidneys (Supplemental Figure 6) or the vasculature (Supplemental Figure 7), as assessed by $\mathrm{H} \& \mathrm{E}$ staining. In male mice, deletion of the Ipr had no significant effect on urinary total nitrate plus nitrite (Supplemental Figure 8A) or on plasma renin levels (Supplemental Figure 8B) compared with $\mathrm{Ldll}^{-1}$ mice.

In contrast to the males, expression levels of corin, ANP, and BNP mRNA in whole heart and of the 3 mitochondrial dysfunction and oxidative phosphorylation genes (Atp5e, Cat, and Sod2) in the renal medulla were not significantly altered between female $\mathrm{Ldlr}^{-/}$and $\mathrm{Ipr}^{-/} \mathrm{Ldlr}^{--}$mice fed a HSD for 2 weeks (Supplemental Figure 9, A-E). Urinary $\mathrm{F}_{2} \mathrm{iP}$ did not differ significantly in female $\mathrm{Ipr}^{-/} \mathrm{Ldlr}^{-/-}$mice compared with $\mathrm{Ldlr}^{-/}$mice at baseline (Supplemental Figure 10A) or after 2 weeks on a HSD (Supplemental Figure 10B). However, combined deletion of Ipr and ANP receptor blockade in female mice significantly increased urinary $\mathrm{F}_{2} \mathrm{iP}$ levels (Supplemental Figure 10C), whereas deletion of the Ipr significantly reduced baseline urinary ANP levels (Supplemental Figure 10D). This difference was abolished after 2 weeks on the HSD (Supplemental Figure 10E); blockade of the ANP receptor did not alter ANP levels between $\mathrm{Ldlr}^{--}$and $\mathrm{Ipr}^{-/} \mathrm{Ldlr}^{-/}$mice (Supplemental Figure 10F). These results were consistent with the failure of genotype to significantly influence the HSD-evoked BP response in female mice (Supplemental Figure 2).

Sex-dependent immunological responses induced by a HSD. Given our findings on sex differences in BP responses, we were interested in comparing the transcriptomic profiles of atria from female and male $\mathrm{Ldlr}^{--}$and $\mathrm{Ipr}^{-/} \mathrm{Ldlr}^{-/}$mice fed a HSD for 2 weeks. We identified 177 DEGs (136 are unique to females, 11 are unique to males, 30 are common between females and males), with a log fold change ranging from 5.00 to -3.84 at a FDR cutoff of 0.4 (Supplemental Figure 11A). In female mice, 110 of the 166 DEGs were downregulated and 56 were upregulated in $\mathrm{Ipr}^{-/} \mathrm{Ldlr}^{-/}$ mice compared with $\mathrm{Ldlr}^{--}$mice. In male mice, 17 of the $41 \mathrm{DEGs}$ were downregulated and 24 were upregulated in $\mathrm{Ipr}^{-/} \mathrm{Ldlr}^{--}$mice. Ingenuity Pathway Analysis revealed the pathways most enriched with DEGs including the antigen presentation pathway, B cell development, and $\mathrm{T}$ cell receptor signaling (Supplemental Figure $11 \mathrm{~B}$ and Table 2). In female mice, DEGs associated with the classical or nonclassical MHC class I molecules including C5ar2, $R f x 5$, H2-M3, H2-Q5, H2-Q6, C5ar1, H2-Aa, H2-Q7, H2-T22, H2-DMb1, $N l r c 5$, and $\mathrm{H} 2-\mathrm{T1O}$ were downregulated in $\mathrm{Ppr}^{-/} \mathrm{Ldlr}^{--}$mice compared with $\mathrm{Ldlr}^{--}$mice, and only C5ar2 was downregulated in male $\mathrm{Ipr}^{--} \mathrm{Ldlr}^{--}$mice (Supplemental Data File 1, atrial DEGs between male and female $\mathrm{Ldlr}^{-/}$and $\mathrm{Ipr}^{--} \mathrm{Ldlr}^{--}$mice on a HSD). We validated the H2-M3 DEG by RT-qPCR (Supplemental Figure 11C). Functional output analysis predicted inflammatory responses and chronic inflammatory disorders as downstream pathways likely to be affected by the DEGs. However, there was not a strong degree of consistency in the directions of the DEGs (Supplemental Figure 11D and Supplemental Table 2). Both Th17 cells and Tregs have been shown to modulate $\mathrm{BP}$ responses in hypertensive mouse models. Depletion of the Ipr significantly increased plasma levels of IL-17A (Supplemental Figure 11E) and cardiac mRNA levels of the IL-17 receptor A (IL-17ra) (Supplemental Figure 11F) and the transcription factor of Tregs (Foxp3) (Supplemental Figure 11G) in male $L d l r^{-/}$mice.

An ANP antagonist rescues hypotension in Ipr-deficient hyperlipidemic mice on a HSD. Given the physiological constraint of implanting both radio telemetry probes and minipumps into mice to monitor BP and deliver the ANP antagonist during HSD feeding, we decided to use the tail-cuff system for the former, while delivering the antagonist by minipump. Despite its lower sensitivity, BP data collected using the tail-cuff system correlated with the data from radio telemetry (Figure $5, \mathrm{~A}$ and $\mathrm{B}$ ).

Inhibition of the endogenous ANP signaling pathway with the antagonist A71915 (27) attenuated the hypotensive response to Ipr deletion in HSD-fed male $\mathrm{Ipr}^{-/} \mathrm{Ldlr}^{-/-}$mice during both the night and day periods (Figure 5, A and B, and Supplemental Figure 12, sham-saline). Consistent with this, we observed no significant differences in mRNA levels of atrial or ventricular corin, ANP, or BNP between male $\mathrm{Ldlr}^{-/}$and $\mathrm{Ipr}^{-/-} \mathrm{Ldlr}^{-/}$mice treated with the antagonist (Supplemental Figure 13, A-F). Similarly, the differences in expression of the Npr1 receptor for ANP in renal medulla (Supplemental Figure 13G), and 3 of the genes (Atp5e, Cat, and Sod2) in the mitochondrial dysfunction and oxidative phosphorylation pathways (Supplemental Figure 14, A-C) were abolished by antagonist administration. Administration of A71915 did not alter plasma creatinine levels 
A

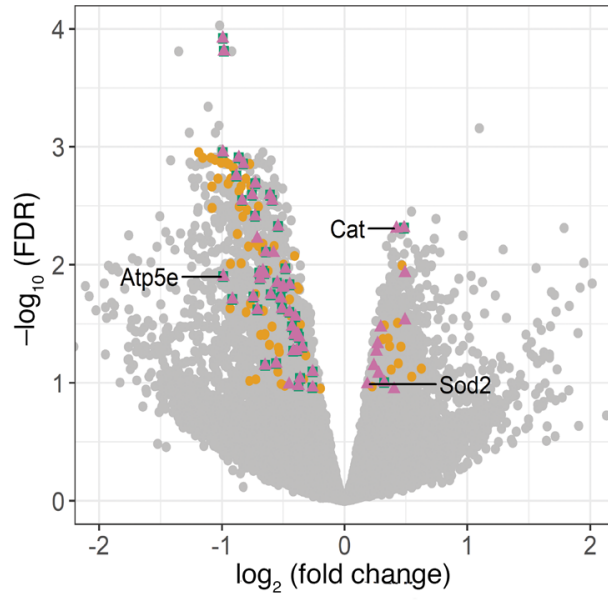

Pathway

- elF2 signaling

- Oxidative phosphorylation

$\triangle$ Mitochondrial dysfunction

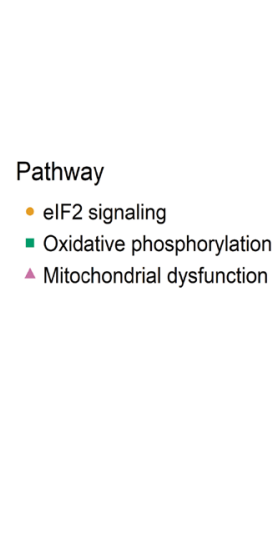

B

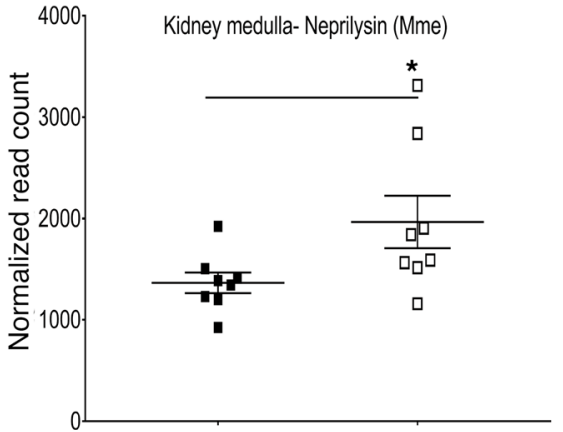

- Ldlr $r^{-\alpha} \quad$ a $l p r^{-1-} L d l r^{--}$
C

$$
\text { - Ldlr } \quad \square / p r^{-1-L d l r^{--}}
$$

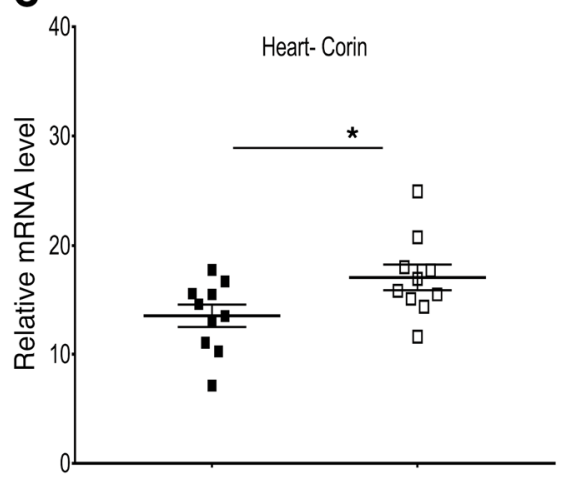

D
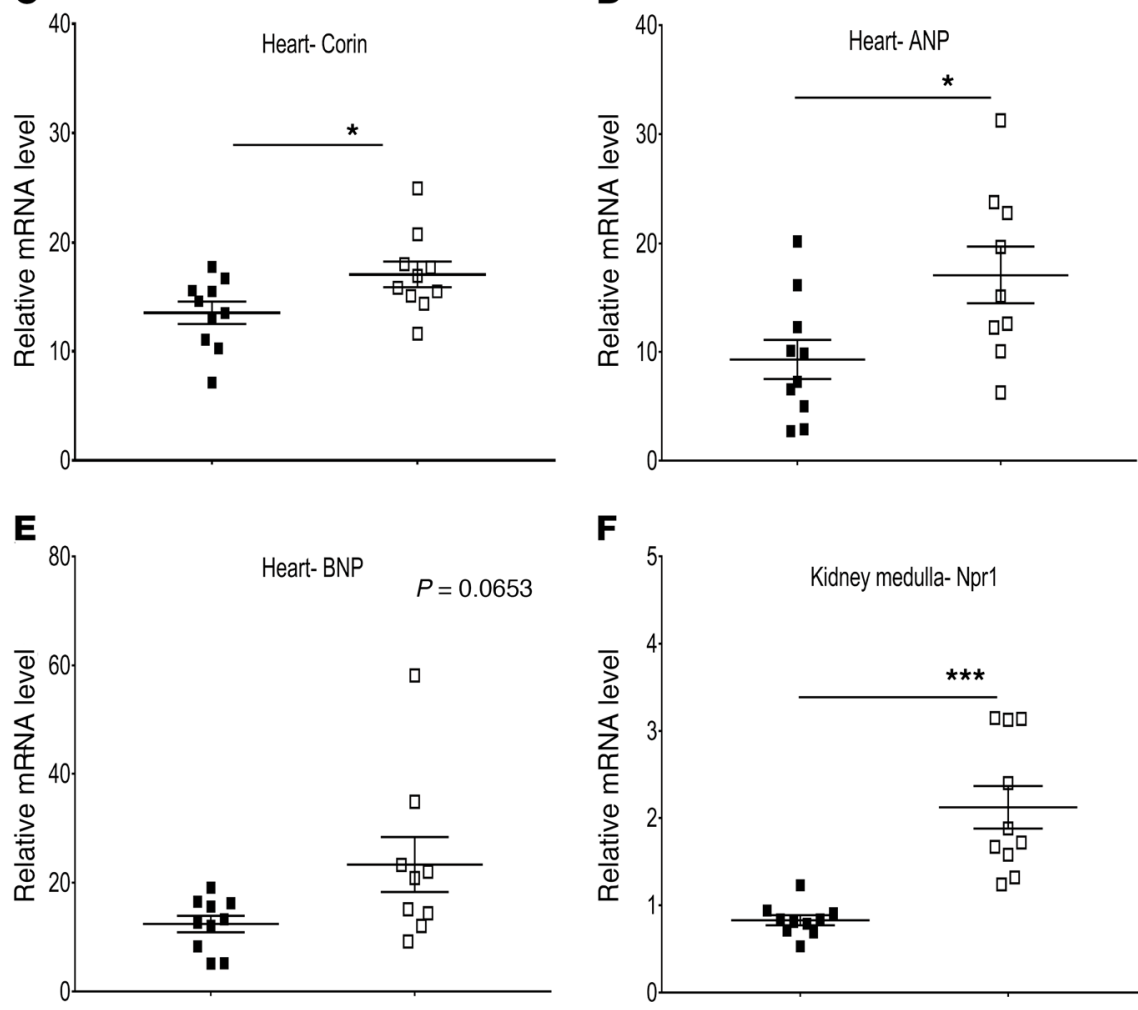

$\mathbf{F}$

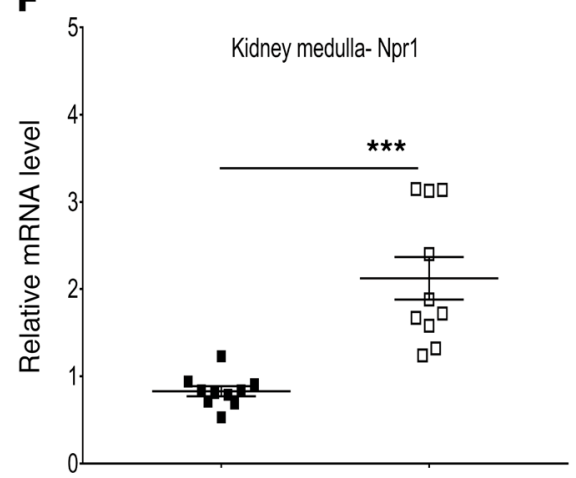

Figure 3. Combined Ipr deletion and saltevoked hypertension downregulates elF2, mitochondrial dysfunction, and oxidative phosphorylation pathways and activates ANP synthesis. RNA samples isolated from kidney medulla of $\mathrm{Ldll}^{-1-}$ and $\mathrm{Ipr^{-1 }} \mathrm{Lddr}^{-1-}$ mice after 2 weeks on a HSD were used for RNA-Seq. (A) Analysis of signaling pathways. A Volcano plot compares the overlap of genes identified in the top 3 canonical pathways: elF2 signaling, mitochondrial dysfunction, and oxidative phosphorylation. Seventy-six genes in the elF2 signaling pathway were unique, 47 genes were common between mitochondrial dysfunction and oxidative phosphorylation, and 13 genes were unique to mitochondrial dysfunction. Atp5e, Cat, and Sod2 are genes validated by RT-qPCR. (B) Neprilysin (Mme) transcript levels were increased in $\mathrm{Ipr}^{-1-} \mathrm{Ldll} \mathrm{r}^{-1-}$ mice compared with levels in $\mathrm{Ldll}^{-1-}$ mice. (C-F) RT-qPCR was performed to measure the expression of corin (ANP-converting enzyme), ANP, and BNP in whole heart and kidney medullary Npr1 (a receptor of ANP). HSD feeding increased corin and $A N P$ transcripts in heart and Npr1 in kidney medulla of $I \mathrm{pr}^{-1-} L d l r^{-1-}$ mice compared with $\mathrm{LdIr}^{-/-}$mice. Expression of the BNP gene was not significantly altered between $L d l r^{-/-}$and $/ \mathrm{pr}^{-}$ $1-L d l r^{-1-}$ mice. Data are expressed as the mean \pm SEM. ${ }^{*} P<0.05$ and ${ }^{* *} P<0.001$, by 2 -tailed parametric test. $n=9-10$ mice per genotype. in male $\mathrm{Ldlr}^{-/-}$or $\mathrm{Ipr}^{-/-} \mathrm{Ldlr^{-/- }}$ mice (Supplemental Figure $13 \mathrm{H}$ ). As expected in female mice, we detected no differences in SBP or plasma creatinine between $\mathrm{Ldlr}^{-/-}$and $\mathrm{Ipr}^{-/-} \mathrm{Ldlr}^{-/-}$mice fed a HSD for 2 weeks in conjunction with ANP receptor blockade (Supplemental Figure 15, A and B).

Detailed statistical analyses of the interactions between BP, genotypes, and treatment (week) in the A71915 study in male mice are described in the Supplemental Methods.

Estrogen protects female hyperlipidemic mice from salt-evoked hypertension. To address the female BP phenotypes, we performed the HSD experiment using OVX mice. The HSD significantly increased BP responses in OVX $\mathrm{Ldlr/-}$ mice in week 2 compared with baselineduring both the active and resting periods (Figure 5, CandD).
Deletion of the Ipr augmented the SBP responses, and supplementation with estradiol (E2) significantly restrained these responses (Figure 5, C and D). Similar differences in DBP responses were observed in $\mathrm{Ldlr}^{--}$and Ipr-deficient $\mathrm{Ldlr}^{-/-}$mice (Figure 5, E and F). As expected, we detected no significant differences in BP responses among the sham-operated mice fed a HSD for 2 weeks (Supplemental Figure 16, A-D).

Detailed statistical analyses of the interactions among geno-

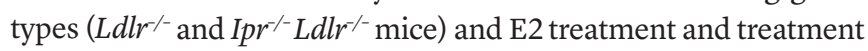
week of OVX mice are described in the Supplemental Methods.

HSD alters gut microbiota composition in a sex-dependent manner

To study the impact of sex and Ipr depletion on the gut microbi- 

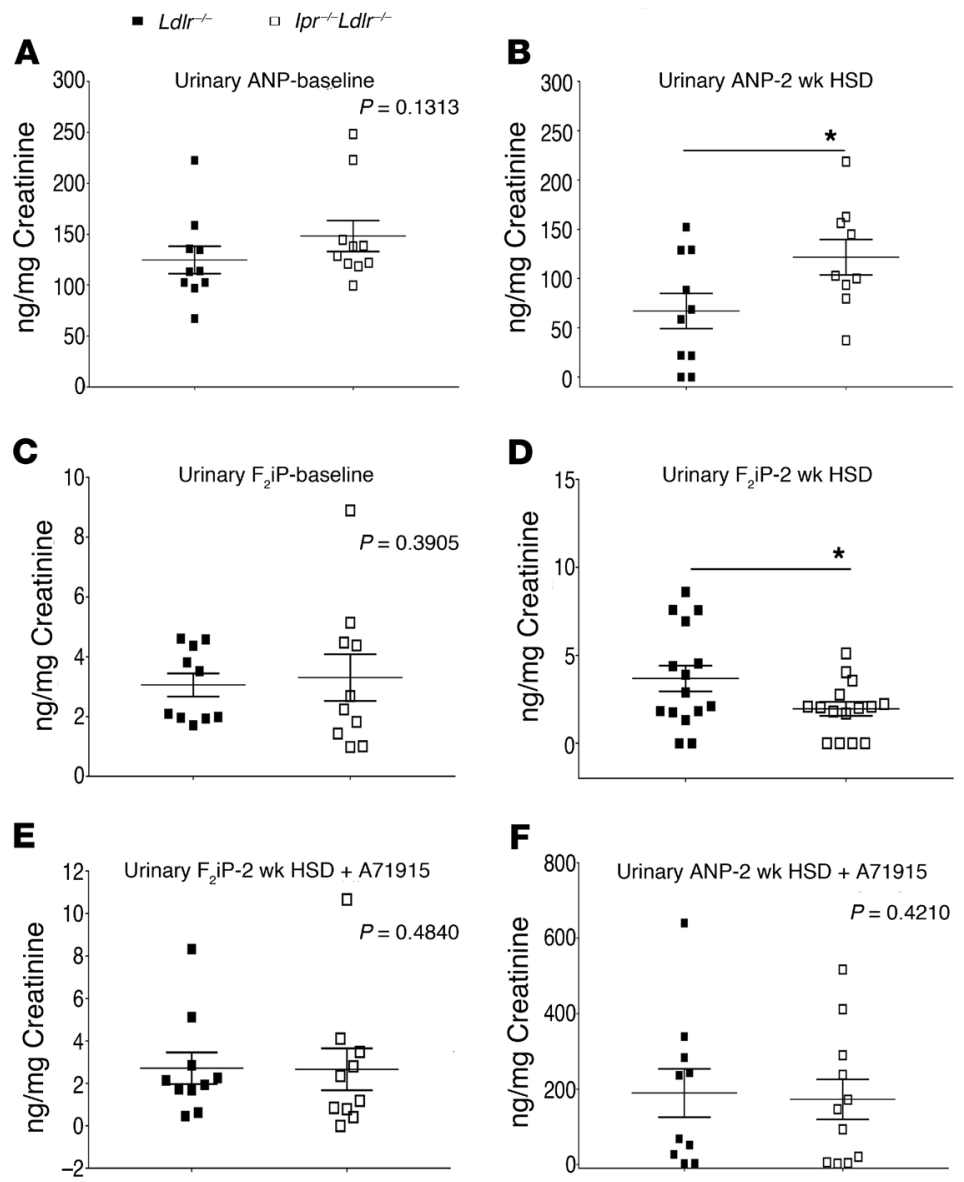

Figure 4. Combined deletion of Ipr and salt-evoked hypertension increases urinary ANP and reduces $\mathbf{F}_{2}$ iPs. Urinary ANP levels at (A) baseline and (B) 2 weeks after a HSD were measured using an ELISA kit. Urinary ANP levels were elevated in $\mid \mathrm{pr}^{-1-} \mathrm{Ldll}^{-/-}$mice compared with levels in $\mathrm{Ldll}^{-/-}$mice 2 weeks after HSD feeding. An abundant urinary $\mathrm{F}_{2} \mathrm{iP}(8,12-i$ iso-iPF$\alpha-\mathrm{VI})$ was analyzed by LC-MS/MS as described in Methods. (C and $\mathbf{D})$ Urinary $\mathrm{F}_{2}$ iP levels were not altered in $\mid \mathrm{pr}^{-1-}$ Ldl $^{-1-}$ mice compared with $L d l r^{-1-}$ mice at baseline, but urinary $\mathrm{F}_{2}$ iP levels in $\mathrm{pr}^{-1-} \mathrm{Ldll}^{-1-}$ mice were significantly reduced after 2 weeks on a HSD. Treatment with the ANP receptor antagonist A71915 (50 $\mu \mathrm{g} / \mathrm{kg} \mathrm{BW} /$ day) abrogated the reduction of $(\mathbf{E})$ urinary $F_{2}$ iPs and $(\mathbf{F})$ urinary ANP in $I \mathrm{pr}^{-1-}$ Ldlr ${ }^{-1-}$ mice. Data are expressed as the mean \pm SEM. ${ }^{*} P<0.05$, by 1-tailed parametric test with Welch's correction. $n=9-15$ mice per genotype. A 1-tailed parametric test was performed for urinary $F_{2} i P$ and ANP levels, because both mediators had already been shown to restrain oxidative stress in the vasculature.

ome in our mouse model of salt-evoked hypertension, we subjected female and male $\mathrm{Ldlr}^{--}$and $\mathrm{Ipr}^{-/} \mathrm{Ldlr}^{--}$mice to a HSD for 2 weeks. We analyzed fecal samples on day 0 and day 14 by 16S rRNA marker gene sequencing. The taxonomic identities of prominent amplicon sequence variants (ASVs) are presented in the heatmap in Supplemental Figure 17 (mean relative abundance among all parameters of $>0.5 \%$ ). A comparison of the microbiome on day 0 versus day 14 revealed that a HSD was associated with decreased $\alpha$-diversity (Faith's phylogenetic diversity [PD]) in

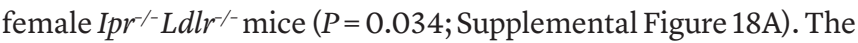
bacterial community, as analyzed by unweighted and weighted UniFrac, was different between day 0 and day 14 in both sexes and genotypes (Figure 6, A and B). At the genus level, the relative abundance of Lactobacillus decreased in male $\mathrm{Ldlr}^{-/}$mice $\left(P=1.2 \times 10^{-3}\right.$; Figure 6C) and $\mathrm{Ipr}^{-1-} \mathrm{Ldlr^{-1 }}$ mice $\left(P=2.5 \times 10^{-4}\right.$; Figure 6C), but not in female mice. Several taxa were changed over time in both sexes and genotypes: Bacteroidales S24-7and Staphylococcus increased in relative abundance, whereas Mucispirillum and Helicobacter decreased. Corynebacterium was detected only in male mice and increased after HSD feeding (Supplemental Figure 18B).

When we examined the effect of sex on the gut microbiota after HSD feeding, we found that the $\alpha$-diversity between female and male mice was not different (Supplemental Figure 18C), but we did detect differences in $\beta$-diversity (unweighted UniFrac) on day 0 in $\mathrm{Ldlr}^{-/}$mice $(P$ $=0.01)$ and on day 14 in $\mathrm{Ipr}^{-/-} \mathrm{Ldlr^{-/ }}$ mice $(P=0.01$, Supplemental Figure 18D). On day 14, the relative abundance of Lactobacillus was decreased $(P=0.03)$ in male $\mathrm{Ipr}^{-/} \mathrm{Ldlr}^{-1}$ mice compared with females (Supplemental Figure 18E). To gain further insight into the types of Lactobacillus observed, we aligned representative sequences from our experiment to species-type strains and assigned species where our sequences matched within $2 \mathrm{bp}$. Thus, we observed a decrease in sequences consistent with Lactobacillus intestinalis $\left(P=1.6 \times 10^{-4}\right)$ in male $\mathrm{Ldlr}^{-/}$mice relative to female mice (Supplemental Figure 18F). We found no differences in $\alpha$-diversity or $\beta$-diversity between $\mathrm{Ldlr}^{-/}$and $\mathrm{Ipr}^{-1} \mathrm{Ldlr}^{--}$ mice on day 0 or day 14 in female or male mice (Supplemental Figure 19, A and B).

A HSD alters microbiota-derived fecal indole metabolites and short-chain fatty acids. As a HSD significantly reduced the abundance of Lactobacillus in male mice compared with female mice, regardless of genotype, we were interested in measuring microbiota-derived fecal indole metabolites and short-chain fatty acids (SCFAs) by liquid chromatography tandem mass spectrometry (LC-MS/MS) and $\mathrm{H}^{1}-\mathrm{NMR}$, respectively. Since Ipr deletion did not alter both $\alpha$ - and $\beta$-diversity of the gut microbiota in female or male mice, we combined both genotypes in our analyses to determine the effect of a HSD on fecal metabolites. As shown in Figure 6D, a HSD significantly increased fecal indole-3-acetic acid (IAA), whereas indole-3-propionic acid (IPA) was decreased in both female and male mice. However, indole-3lactic acid (ILA) was significantly decreased only in male mice. Consistent with the decreased abundance of Lactobacillus, we found that fecal lactic acid contents were significantly reduced in both female and male mice after HSD feeding (Supplemental Figure 20, A and B). We observed a similar pattern for fecal butyric acid, but only in male mice was a significant reduction attained. Fecal acetic and propionic acids were unaltered in both sexes.

A HSD differentially alters plasma metabolites in female and male mice. The effects of Ipr deletion and sex differences on metabolic activity were further analyzed using plasma samples and ultraperformance liquid chromatography tandem mass spectrometry (UPLC-MS/MS) in a semitargeted approach. Orthogonal partial least-squares discriminant analysis (OPLS-DA) of genotype and sex revealed a distinct separation between female $\mathrm{Ldlr}^{\circ-}$ (red spheres) and male $\mathrm{Ldlr}^{-}$(green spheres) mice after 2 weeks on a HSD (Supplemental Figure 21A and Supplemental Data File 2, plasma 
Table 2. Top canonical pathways predicted by Ingenuity Pathway Analysis for the 177 DEGs in atria between female LdIr $^{\prime-}$ and Ipr ${ }^{\prime-}$

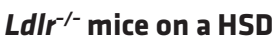

$\begin{array}{lccc}\text { Canonical pathway } & \boldsymbol{P} \text { value } & \text { Overlap } & \text { Molecules represented } \\ \text { Antigen presentation } & 2.57 \times 10^{-8} & 6 / 27 & \text { H2-Q2, H2-DMb1, H2-Aa, H2-M3, Nlrc5, Psmb9 } \\ \text { B cell development } & 2.45 \times 10^{-5} & 4 / 25 & \text { H2-Q2, H2-DMb1, H2-Aa, Ptprc } \\ \text { T cell receptor signaling } & 2.75 \times 10^{-5} & 9 / 148 & \text { Grap2, H2-T10, H2-T22, H2-Q2, H2-DMb1, H2-Aa, H2-M3, Prkcq, Ptprc }\end{array}$

Six of the 27 genes associated with antigen presentation signaling pathway were differentially expressed in $I p r^{-/-} L d l r^{-/-}$mice compared with $L d l r^{-/-}$mice.

metabolites between male and female $\mathrm{Ldlr}^{-/-}$and $\mathrm{Ipr}^{-/-} \mathrm{Ldlr}^{-/-}$mice on a HSD). The OPLS-DA loadings plot showed that indoxyl sulfate, trimethylamine oxide, propylene glycol, and methyl adenosine metabolites were higher in female $\mathrm{Ldlr}^{-/}$mice (Supplemental Figure 21B). Metabolites such as orotate, deoxyuridine, cytidine, carnitine, and so on, on the right side of the plot $(\mathrm{P} 1>0)$ were significantly higher in the male $\mathrm{Ldlr}^{\text {/- }}$ mice. MetaboAnalyst pathway analysis revealed several metabolic differences between female and male mice, including metabolic pathways for phenylalanine, tyrosine, tryptophan, and pyrimidine (Supplemental Figure 21C). Notably, "tryptophan metabolite" was one of the most affected metabolic pathways between female and male $\mathrm{Ldlr}^{--}$mice after 2 weeks on a HSD. To corroborate with our microbiota-induced changes in indole metabolites, we focused on the tryptophan/indole pathway. Indeed, consistent with the reduction in abundance of Lactobacillus, plasma levels of indoxyl sulfate/tryptophan (Figure 6E) were significantly decreased in male $\mathrm{Ldlr}^{-}$mice compared with levels in female $\mathrm{Ldlr}^{-}$mice, whereas tryptophan and kynurenine levels were not altered between female and male mice, regardless of their genotype (Supplemental Figure 21D).

\section{Discussion}

NSAIDs represent an alternative to opioid analgesics, but they confer a cardiovascular hazard attributable to suppression of COX-2-derived cardioprotective prostaglandins, especially $\mathrm{PGI}_{2}$ (30). $\mathrm{PGI}_{2}$ restrains platelet activation and is a vasodilator; deletion of its Ipr predisposes normolipidemic mice to thrombogenic and hypertensive stimuli $(3,31,32)$. Given the importance of $\mathrm{PGE}_{2}$ as a mediator of pain and inflammation, interest has focused on the development of inhibitors of mPGES-1, the enzyme downstream of COX-2 that is the dominant source of $\mathrm{PGE}_{2}$ biosynthesis $(1,2)$.

In normolipidemic mice, deletion of mPges-1, unlike deletion of COX-2 or the Ipr, has a bland adverse cardiovascular profile; it does not promote thrombogenesis, and it restrains atherogenesis $(3,33)$. This reflects rediversion of the $\mathrm{PGH}_{2}$ substrate of mPGES-1 to other prostaglandin synthases, most relevantly to augment $\mathrm{PGI}_{2}$ biosynthesis (34). Depending on the genetic background, it may leave basal and evoked $\mathrm{BP}$ responses unchanged or modestly increased. On a hyperlipidemic background, increased $\mathrm{PGI}_{2}$ limits thrombogenesis, while suppression of $\mathrm{PGE}_{2}$ accounts for the restraint of atherogenesis when mPges-1 is deleted (9). Inhibition of mPGES-1 in humans also augments biosynthesis of $\mathrm{PGI}_{2}$ coincident with suppression of $\mathrm{PGE}_{2}(35)$.

Initially, we wished to examine the impact of mPges-1 deletion on $\mathrm{BP}$ in hyperlipidemic mice. Both $\mathrm{PGE}_{2}$ and $\mathrm{PGI}_{2}$ may act as vasodilators, and deletion of their Epr2 and Ipr receptors predispose normolipidemic mice to HSD-induced elevations of $\mathrm{BP}(31,32,36)$. Here, we found that mPges-1 deletion predisposed hyperlipidemic male, but not female, mice to the pressor response to a $\mathrm{HSD}$, consistent with the role of $\mathrm{PGE}_{2}$ in fluid volume and BP homeostasis (37). Moreover, chronic exposure to a pharmacological inhibitor (MF970) specifically targeting human mPGES-1 resulted in elevated SBP in hyperlipidemic mice on a HFD. These observations raise the possibility that, despite results in healthy volunteers (28), inhibition of MPGES-1 in male patients with hyperlipidemia may predispose them to an exaggerated $\mathrm{BP}$ response to a HSD.

To investigate whether the augmented $\mathrm{PGI}_{2}$ biosynthesis resulting from mPges-1 deletion might be buffering the hypertensive phenotype, we used mice lacking the Ipr. We were surprised to find that $\mathrm{BP}$ responses to salt loading in male, but not female, mice were attenuated (rather than exacerbated) in $\mathrm{Ipr}^{--} \mathrm{mPges}_{-1^{-/-}}$ mice. Deletion of the Ipr resulted in a compensatory increase in the biosynthesis of $\mathrm{PGI}_{2}$ consequent to salt loading. However, given the absence of its receptor, this would be unlikely to directly influence BP homeostasis. Rather, we found activation of another compensatory mechanism increased formation of the vasodilator ANP. Antagonism of its Npr1 receptor was sufficient to rescue the hypotensive response to a HSD in Ipr-depleted mice. The ANP promoter contains cAMP response element-binding sites. Normally, ligation of the Ipr by $\mathrm{PGI}_{2}$ results in activation of protein kinase A (PKA) and elevation of intracellular cAMP (38). In the absence of its cognate receptor, augmented $\mathrm{PGI}_{2}$ levels in male $\mathrm{Ipr}^{-/}$mice may activate other PKA-linked receptors, such as Epr2, Epr4, and Dpr1. Indeed, the HSD also increased the biosynthesis of $\mathrm{PGD}_{2}$ that, acting through the Dpr1, may augment this effect. Thus, altered patterns of eicosanoid formation in Ipr-deficient mice on a HSD may act via this mechanism to effect a compensatory elevation of ANP.

Hyperlipidemia in $\mathrm{Ldlr}^{-/}$mice is associated with oxidative stress, as reflected by increased generation of $\mathrm{F}_{2} \mathrm{iP}$, a biomarker of lipid peroxidation (22). Both $\mathrm{PGI}_{2}$ and ANP can act to restrain oxidative stress, which itself may contribute to an elevation of BP in response to a $\operatorname{HSD}(23,39,40)$. Here, we found that, despite an augmentation of $\mathrm{PGI}_{2}$ biosynthesis, urinary $\mathrm{F}_{2} \mathrm{iP}$ was depressed in $\mathrm{Ipr}^{-1-} \mathrm{Ldlr}^{-/}$mice compared with mice lacking the Ldlr alone. To address the possibility that this reflected the compensatory augmentation of ANP, we treated the mice with an ANP receptor antagonist and found that, like the hypotensive phenotype, it rescued the suppression of $\mathrm{F}_{2} \mathrm{iP}$ in the $\mathrm{Ipr}^{-1} \mathrm{Ldlr}^{-/}$mice. Pathway enrichment analyses of RNA-Seq data also reflected a shift in the 

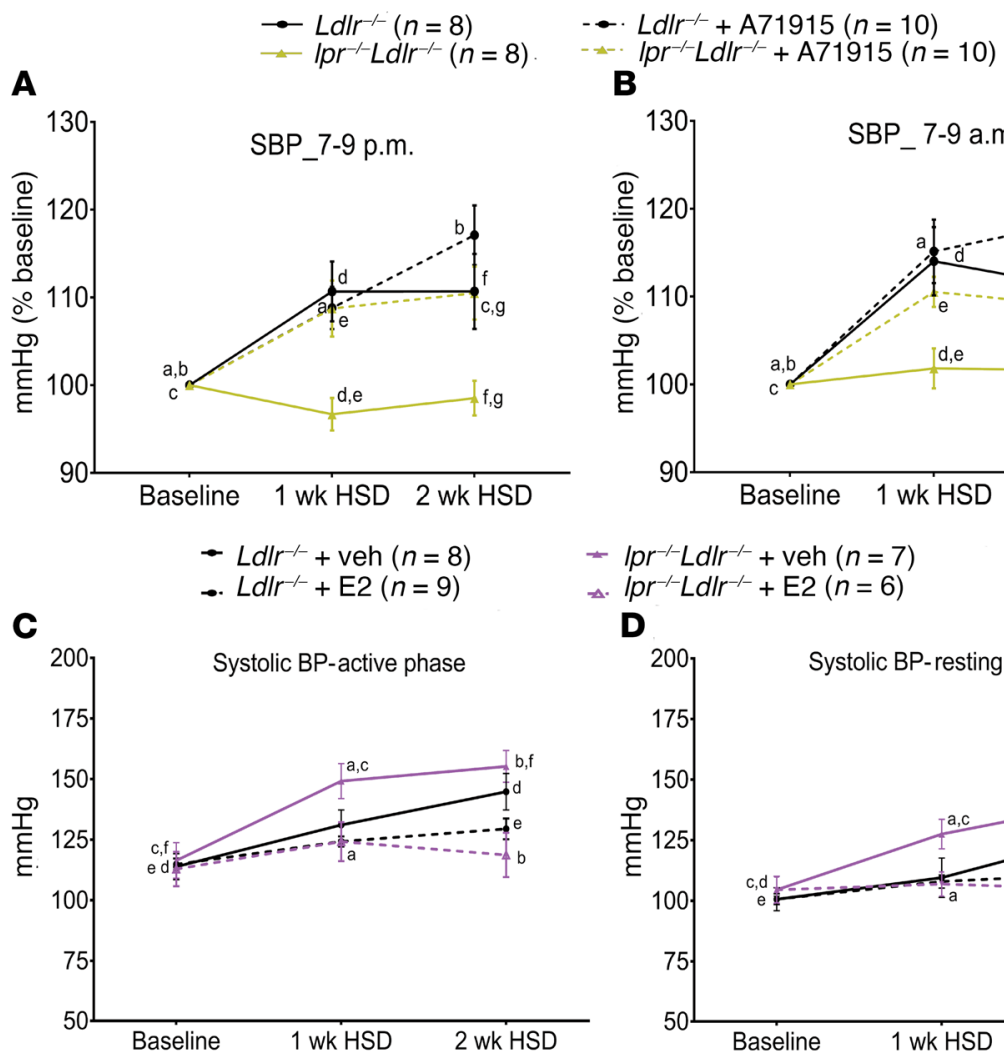

$$
\text { B }
$$
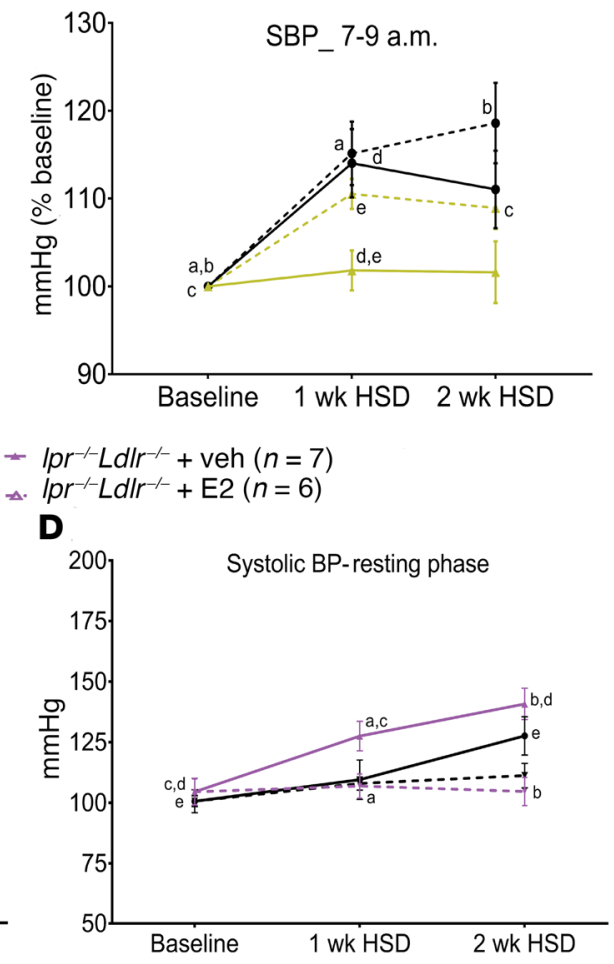

$\mathbf{E}$
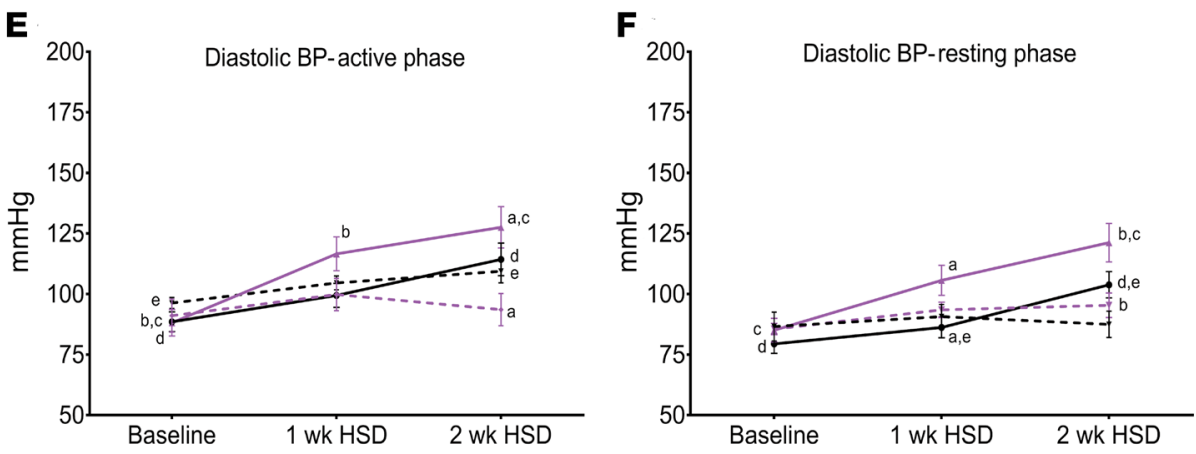

Figure 5. The ANP receptor antagonist A71915 and estrogen mediate salt-evoked BP responses in Ipr-deficient male and female hyperlipidemic mice, respectively. The ANP antagonist A71915 rescued hypotension in $1 \mathrm{pr}^{-1-}$ Ldll $\mathrm{r}^{-1}$ mice fed a HSD. SBPs during (A) the active phase (7 pm-9 pm) and (B) the resting phase $(7 \mathrm{am}-9 \mathrm{am})$ for male mice with and without minipumps were measured using a tail-cuff system before and 1 and 2 weeks after HSD feeding in conjunction with or without ANP inhibition via A71915 infusion ( $50 \mu \mathrm{g} / \mathrm{kg}$ BW/day). To compare the effect of $/ p r$ deletion and A71915 administration, genotype and feeding times with the same lowercase letter denote significant differences $(a-g, P<0.05)$ after 1 week on a HSD or after 2 weeks on a HSD. For example, a - the SBP (active phase) of $I p r^{-1-} \mathrm{Ldll}^{-1-}$ mice was significantly elevated after 1 week on a HSD and b - after 2 weeks on a HSD compared with baseline SBP; $d$ - the SBP (active phase) of $L d l r^{1-}$ mice was significantly elevated compared with the SBP of $I \mathrm{pr}^{-1-} \mathrm{Ldll}^{-1-}$ mice after 1 week on a HSD, etc. Data are expressed as the mean \pm SEM. $n=8-10$ mice per

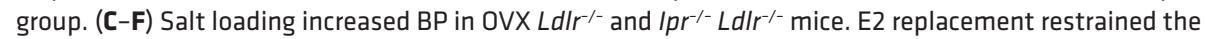
$\mathrm{BP}$ responses. To compare the effect of Ipr deletion and E2 administration, genotype and/or feeding time with the same lowercase letter were significantly different $(a-f, P<0.05)$ after 1 week on a HSD or after 2 weeks on a HSD. For example, a - the SBP (active phase) of Ipr Ldlr-DKO mice treated with vehicle (veh) was significantly higher than the SBP of $I \mathrm{pr}^{-1-} \mathrm{Ldll}^{-1-}$ mice treated with E2 after 1 week on a HSD and b - after 2 weeks on a HSD; c - the SBP (active phase) of $/ \mathrm{pr}^{-1-} \mathrm{Ldll}^{-1-}$ mice treated with vehicle was significantly higher after 1 week on a HSD compared with baseline SBP, etc. Data are expressed as the mean \pm SEM. $n=6-9$ mice per group. redox balance in the renal medulla of these $\mathrm{Ipr}^{-1} \mathrm{Ldlr}^{-1}$ mice. Some 45 genes related to mitochondrial dysfunction and oxidative phosphorylation were downregulated, whereas genes encoding antioxidant enzymes, including mitochondrial SOD2 and catalase, were upregulated. Again, ANP antagonism rescued this signature, adding evidence consistent with an antioxidant effect of functional relevance. Although the ANP/Npr1 pathway plays an important role in regulating blood volume and pressure $(41,42)$, we failed to observe comparative diuresis or natriuresis in the $\mathrm{Ipr}^{-1} \mathrm{Ldlr}^{-1}$ mice. Similarly, urinary total nitrate/nitrite and plasma renin levels were unaltered in the $\mathrm{Ipr}^{-} \mathrm{Ldl} \mathrm{r}^{-}$mice compared with levels in Ldlr/- controls.

These differences in the BP response to a HSD and the attendant changes in gene expression and activation of the ANP pathway were observed only in male mice. There is prior evidence for the influence of sex and genetic background on disruption of the prostaglandin pathways. For example, we have shown that deletion of the Ipr accelerates atherogenesis particularly in female mice because of the importance of $\mathrm{PGI}_{2}$ as a mediator of estrogen receptor-dependent cardioprotection (23).

Estrogen increases vasodilation partly by binding to its receptors in vascular endothelial and smooth muscle cells (SMCs) of the vasculature (43). Consistent with the findings that estradiol activates $\mathrm{PGI}_{2}$ biosynthesis in rat aortae (44), rat aortic SMCs (45), and human endothelial cells (46), ovariectomy augmented the hypertensive response to a HSD in $\mathrm{Ldlr}^{--}$and Iprdeficient $\mathrm{Ldlr}^{-/}$mice. Estradiol replacement restrained the elevation in $\mathrm{BP}$ in the OVX mice, consistent with our observation of sexual dimorphism in the response to Ipr deletion and the $\mathrm{BP}$ response to a HSD.

Increasing evidence suggests that $\mathrm{T}$ cells mediate inflammatory processes associated with hypertension in humans $(16,47,48)$. Rodent models of hypertension have also been associated with the upregulation of pathogenic Th17 cells and the downregulation of protective Tregs (16, 49-51). Here, 
A

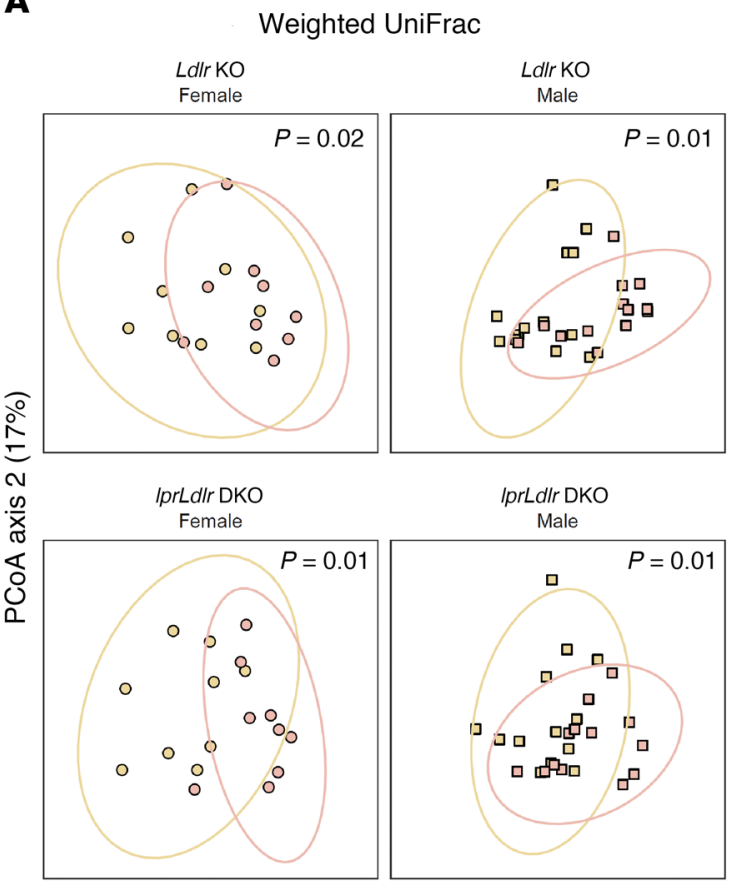

PCoA axis $1(36 \%)$
B

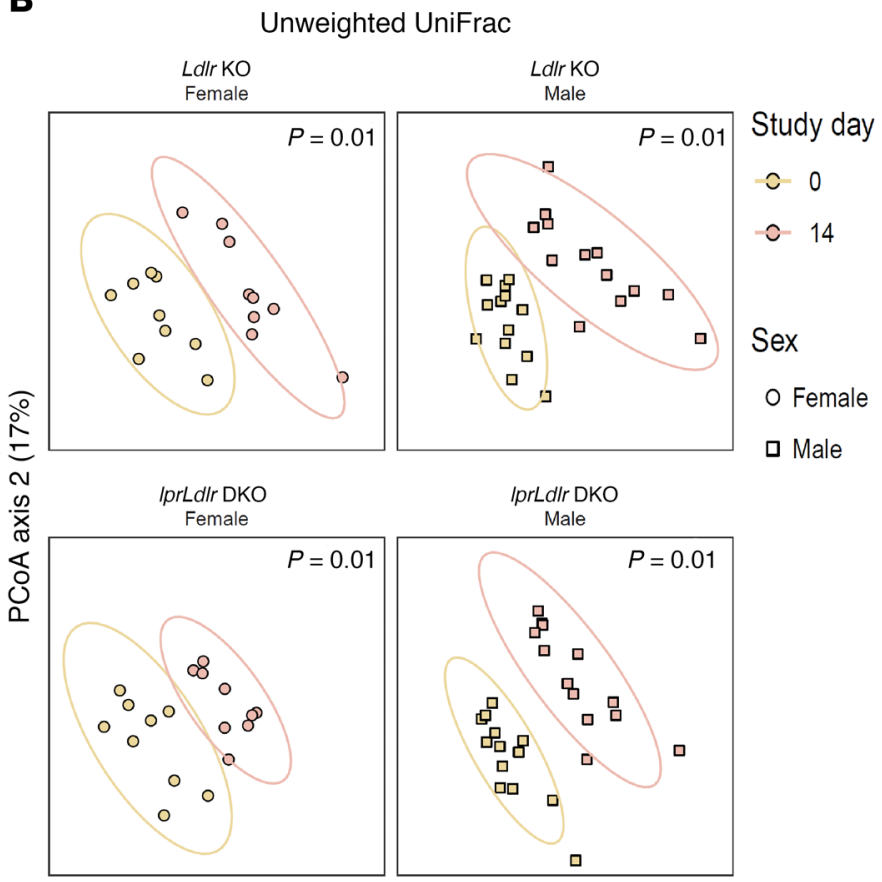

PCoA axis $1(8 \%)$
C

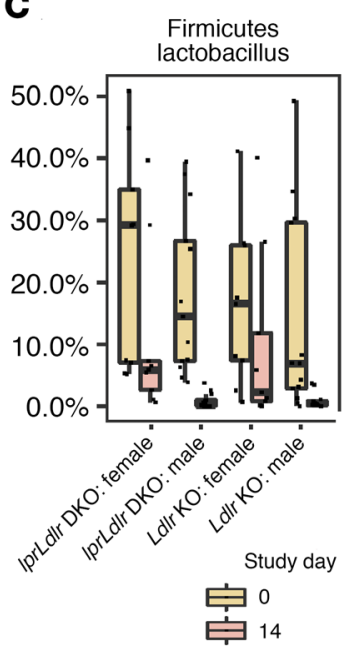

D

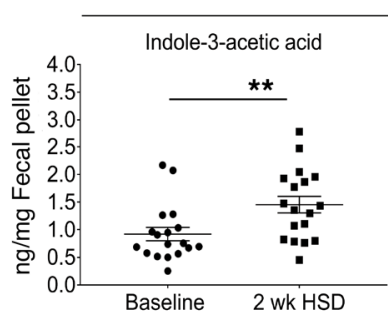

Female



Male

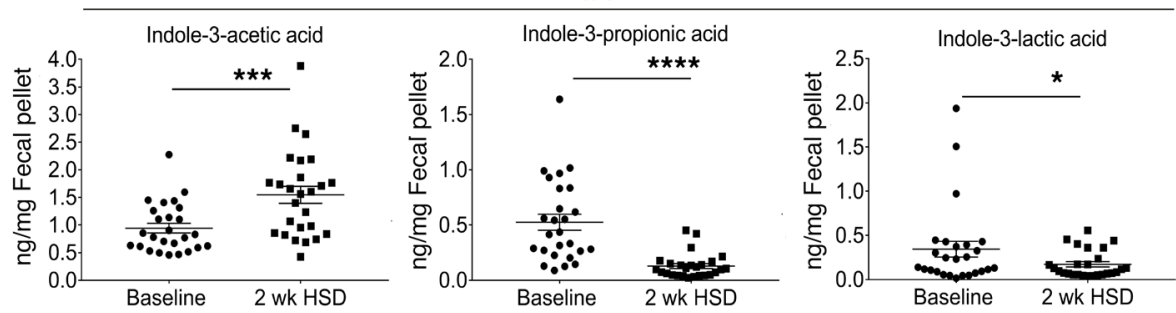

$\mathbf{E}$

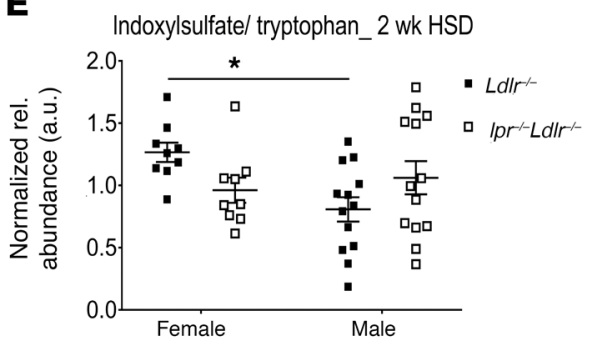

Figure 6. A HSD alters gut microbiota composition in a sex-dependent manner. Fecal pellets were collected from singly housed mice at baseline (day 0 ) and 2 weeks (day 14) after HSD feeding. Bacterial DNA was extracted and analyzed by 165 rRNA gene sequencing. Regardless of sex or genotype, $L d l r^{-1-}(L d l r-K O)$ versus $/ p^{-1-} L d l r^{-1-}(I p r$ Ldlr-DKO) mice), $\beta$-diversity of the gut microbiota was significantly different between day 0 and day 14 as assessed by (A) weighted UniFrac and (B) unweighted UniFrac. (C) The relative abundance of Lactobacillus was significantly reduced in male

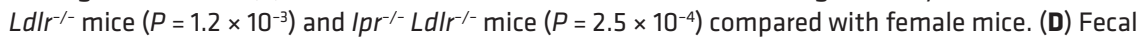
indole metabolites were analyzed by HPLC-MS/MS. HSD feeding significantly increased IAA in both female and male mice, whereas IPA decreased. ILA was significantly reduced in male mice only. As HSD reduces the abundance of Lactobacillus, we performed a 1-tailed test for fecal indole metabolites. Data are expressed as the mean \pm SEM. ${ }^{*} P<0.05$, ${ }^{* *} P<0.01,{ }^{* *} P<0.001$, and ${ }^{* * * *} P<$ 0.0001 , by paired, 1-tailed parametric test. $n=18$ female mice and $n=26$ male mice per genotype. (E) Plasma levels of indoxyl sulfate/tryptophan were significantly reduced in male $\mathrm{Ldll}^{-1-}$ mice compared with levels in female $L d l r^{-/-}$mice after 2 weeks on a HSD. ${ }^{*} P<0.05$. A 2-way ANOVA showed a significant effect of sex on plasma levels of indoxyl sulfate/tryptophan in $\mathrm{Ldll}^{-1-}$ mice. Sidak's multiple comparison tests were used to test significant differences between the sexes. Data are expressed as the mean \pm SEM. $n=9$ female mice and $n=13$ male mice per genotype. PCoA, principal coordinates analysis. 

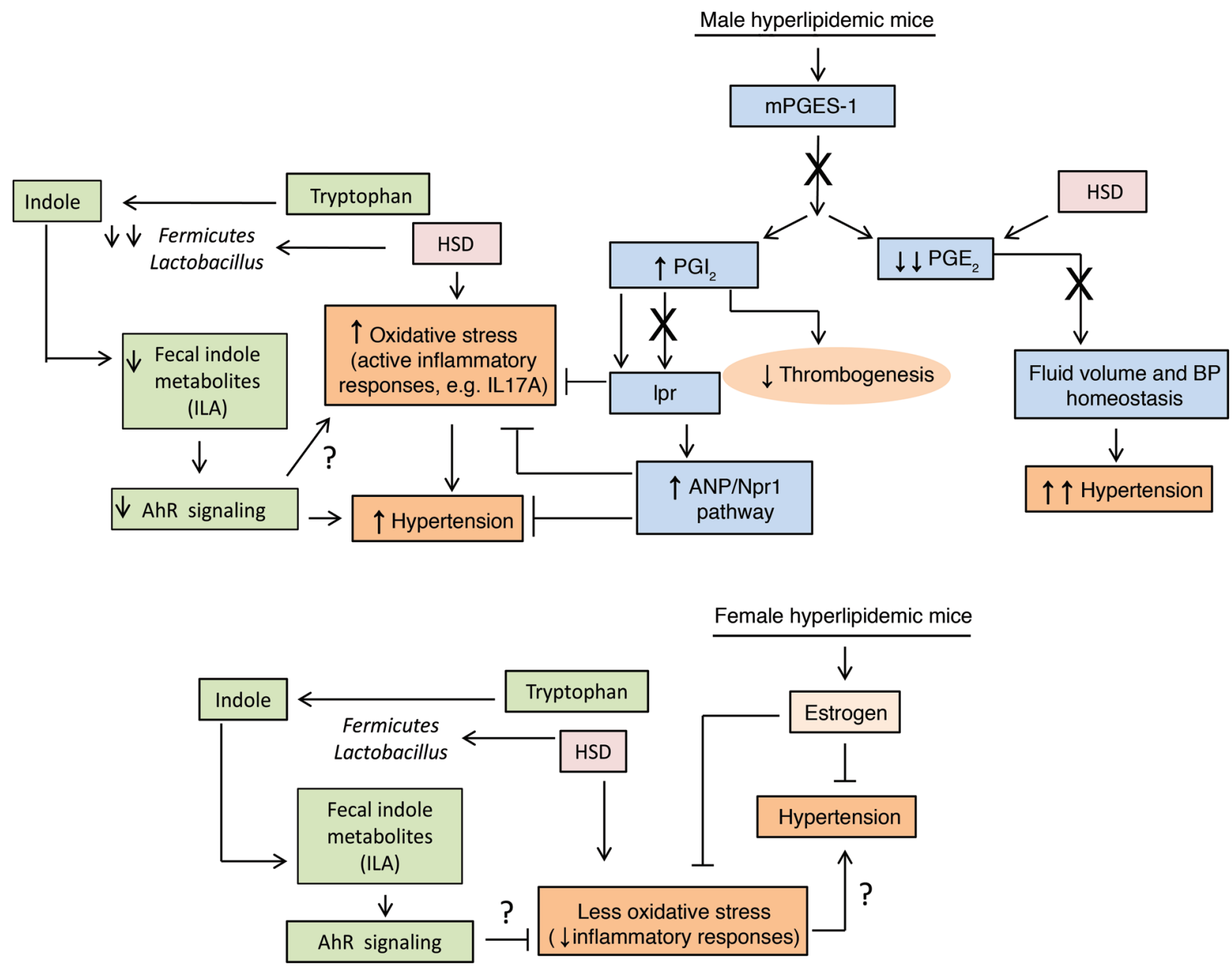

Figure 7. Schema depicting the effect of a $\mathrm{HSD}$ on $\mathrm{PGI}_{2}$ receptor-deficient male and female mice. Deletion of mPges-1 suppressed PGE ${ }_{2}$ biosynthesis, while increasing $\mathrm{PGI}_{2}$, which contributed to the attenuation of thrombogenesis in hyperlipidemic mice. However, salt loading suppressed PGE ${ }_{2}$ biosynthesis and increased $\mathrm{BP}$ responses. Both $\mathrm{PGI}_{2}$ and ANP are vasodilators and restrain oxidative stress induced by a HSD. Deletion of the Ipr resulted in a compensatory increase in ANP/Npr1 signaling and reduced mitochondrial oxidative stress and BP responses. In female hyperlipidemic mice, estrogen protected

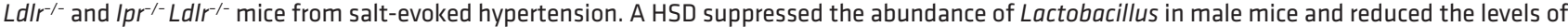
indole metabolites such as ILA. ILA binds the AhR and activates signaling pathways that might restrain oxidative stress and hypertension. Large " $\mathrm{X}$ " symbols indicate inhibition or deletion of an enzyme, and horizontal lines with vertical end bars indicate restraint.

deletion of the Ipr increased serum Il17a and cardiac Il17ra mRNA levels in male $\mathrm{Ldll}^{-}$- mice, consistent with $\mathrm{PGI}_{2}$ restraint of salt-induced oxidative stress and the differentiation of naive $\mathrm{T}$ cells into pathogenic Th17 cells. We speculate that the increase in cardiac Foxp3 mRNA levels, a transcription factor of Tregs, may reflect a response to counteract the increase in Th17 cells. In an airway allergen-sensitive mouse model, $\mathrm{PGI}_{2}$ signaling promoted the differentiation of suppressive Tregs via the Fxop3 transcription factor to restrain immunoglobulin-like transcript 3-driven (ILT3-driven) allergic inflammation (52). Others have shown that female rats with increased Treg numbers were protected from deoxycorticosterone acetate (DOCA) salt-evoked hypertension compared with male rats (47). Here, deletion of the IPr also perturbed the immune profile of atrial transcripts in a sexually dimorphic manner. For example, "antigen presentation pathway," "B cell development," and "T cell receptor signaling" were enriched in hyperlipidemic females by deletion of the IPr.
Additionally, DEGs associated with the classical or nonclassical MHC class I molecules were downregulated in female mice compared with male mice.

Although deletion of the Ipr failed to alter HSD-induced changes in the composition of gut microbiota in $\mathrm{Ldll}^{-/}$mice, HSD had a sexually dimorphic impact on the gut microbiome. Consistent with other studies $(47,53)$, we observed a substantial decrease in the abundance of Lactobacillus in male, but not female, mice fed a HSD for 2 weeks. Lactobacillus is able to metabolize tryptophan to indole metabolites, including IAA, IPA, and ILA, which act via binding to the aryl hydrocarbon receptor (AhR) to modulate innate and adaptive immune responses (54). For example, ILA-producing Lactobacillus murinus was reported to restrain HSD-induced inflammatory Th17 cells in the spleen, small intestine, and colon and rescue salt-sensitive hypertension in FVB/ $\mathrm{N}$ male mice (47). Importantly, ILA induces the differentiation of $\mathrm{CD} 4^{+} \mathrm{Th}$ cells into double-positive intraepithelial lymphocytes via binding to the 
AhR. This effect was abrogated in AhR-deficient Th cells (55). Correspondingly, indoxyl sulfate/tryptophan was reduced in the plasma of male mice, consistent with a differential impact on tryptophan metabolism contributing to the sensitivity of BP to a HSD in male $\mathrm{Ldlr}^{--}$mice. Previous clinical studies have demonstrated that fecal microbiota-derived indole metabolites may activate the AhR to modulate different immune responses in health and disease $(56,57)$.

In summary, we report distinct sex-dependent compensatory mechanisms to preserve $\mathrm{BP}$ homeostasis in response to disruption of the receptor for the direct vasodilator $\mathrm{PGI}_{2}$ (Figure 7). In male mice, deletion of the Ipr restrains salt-evoked hypertension via activation of the ANP/Npr1 pathway, thereby reducing the oxidative stress characteristic of hyperlipidemia. It remains to be seen whether this compensatory response wanes under conditions of chronic intake of a HSD, as might be most clinically relevant. In female mice, estrogen restrains the BP responses of both $\mathrm{Ldlr}^{-/-}$and $\mathrm{Ipr}^{-/-} \mathrm{Ldlr}^{-/-}$mice to saltevoked hypertension. Irrespective of the impact of Ipr deletion, depletion of Lactobacillus in the gut results in perturbation of tryptophan metabolism that may exaggerate the hypertensive response of male mice to a HSD.

Finally, our findings with mPges-1 deletion or pharmacological inhibition of the enzyme in mice suggest that hyperlipidemic male patients consuming a HSD may be susceptible to hypertension when taking mPGES-1 inhibitors.

\section{Methods}

All reagents used were purchased from MilliporeSigma unless otherwise stated.

Detailed descriptions of the animal models and experimental methods are provided in the Supplemental Methods.

RNA-Seq data availability. RNA-Seq data were deposited in the NCBI's Gene Expression Omnibus (GEO) database (GEO GSE115916).

Statistics. All animals were the same age and on the same LdIrbackground (C57BL/6). Where conclusions involved multiple factors, a 2-, 3-, or 4-way repeated-measures ANOVA was performed to assess changes in mean scores at multiple time points and differences in mean scores under multiple conditions. The residuals were normally distributed as required by ANOVA. The degrees of freedom were corrected using Greenhouse-Geisser estimates of sphericity. ANOVAs were repeated on multiple restricted models to assess the effects of combinations of factors. Post hoc analysis was performed using pairwise $t$ tests with Bonferroni's correction unless otherwise stated. A significance threshold of 0.05 was used for all tests. Significance of greater than 0.01 is indicated by double asterisks on the graphs and significance of greater than 0.001 is indicated by triple asterisks unless otherwise stated. Sample sizes were based on power analysis from estimates of the variability of the measurements, and the desire to detect a minimal $10 \%$ difference in the variables was assessed with $\alpha=0.05$ and the power $(1-\beta)=0.8$.

Study approval. All animals in this study were housed according to University of Pennsylvania IACUC guidelines, and all experimental protocols were approved by the IACUC of the University of Pennsylvania (protocol 804754).

\section{Author contributions}

SYT, HM, STA, DS, SG, NFL, KNT, VT, and GRG acquired and analyzed the data. SYT, ER, EJH, KB, AW, and GAF contributed to data interpretation. SYT and GAF conceived the study and are responsible for the experimental design and manuscript preparation.

\section{Acknowledgments}

We gratefully acknowledge the advice of Matthew Palmer (Hospital of the University of Pennsylvania) regarding mouse kidney morphology and the technical support of Weili Yan, Helen Zhou, and Wenxuan Li-Feng. This work was supported by a grant from the NIH (HL062250). GAF is the McNeil Professor of Translational Medicine and Therapeutics.

Address correspondence to: Garret A. FitzGerald, Institute for Translational Medicine and Therapeutics, Perelman School of Medicine, 10-110 Smilow Center for Translational Research, 3400 Civic Center Blvd, Bldg 421, University of Pennsylvania, Philadelphia, Pennsylvania 19104-5158, USA. Phone: 215.898.1184; Email: garret@upenn.edu. DS’s present address is: National Institute on Aging, National Institutes of Health, Baltimore, Maryland 21224, USA.
1. Samuelsson B, et al. Membrane prostaglandin E synthase-1: a novel therapeutic target. Pharmacol Rev. 2007;59(3):207-224.

2. Koeberle A, Werz O. Perspective of microsomal prostaglandin E2 synthase-1 as drug target in inflammation-related disorders. Biochem Pharmacol. 2015;98(1):1-15.

3. Cheng Y, et al. Cyclooxygenases, microsomal prostaglandin E synthase-1, and cardiovascular function. JClin Invest. 2006;116(5):1391-1399.

4. Grosser T, et al. Time for nonaddictive relief of pain. Science. 2017;355(6329):1026-1027.

5. FitzGerald GA. COX-2 and beyond: approaches to prostaglandin inhibition in human disease. Nat Rev Drug Discov. 2003;2(11):879-890.

6. Armstrong EP, Malone DC. The impact of nonsteroidal anti-inflammatory drugs on blood pressure, with an emphasis on newer agents. Clin Ther. 2003;25(1):1-18.

7. Johnson AG, et al. Do nonsteroidal anti-inflam- matory drugs affect blood pressure? A metaanalysis. Ann Intern Med. 1994;121(4):289-300.

8. Pope JE, et al. A meta-analysis of the effects of nonsteroidal anti-inflammatory drugs on blood pressure. Arch Intern Med. 1993;153(4):477-484.

9. Tang SY, et al. Cardiovascular consequences of prostanoid i receptor deletion in microsomal prostaglandin E synthase-1-deficient hyperlipidemic mice. Circulation. 2016;134(4):328-338.

10. von Eiff AW, et al. 1986. Ambulatory blood pressure in children followed for 3 years. Influence of sex and family history of hypertension. Clin Exp Hypertens A. 1986;8(4-5):577-581.

11. Myers J, Morgan T. The effect of sodium intake on the blood pressure related to age and sex. Clin Exp Hypertens A. 1983;5(1):99-118.

12. Dahl LK, et al. Role of the gonads in hypertension-prone rats. J Exp Med. 1975;142(3):748-759.

13. Haywood JR, Hinojosa-Laborde C. Sexual dimorphism of sodium-sensitive renal-wrap hyperten- sion. Hypertension. 1997;30(3 Pt 2):667-671.

14. Stock JL, et al. The prostaglandin E2 EP1 receptor mediates pain perception and regulates blood pressure. JClin Invest. 2001;107(3):325-331.

15. Bartolomaeus $\mathrm{H}$, et al. Precarious symbiosis between host and microbiome in cardiovascular health. Hypertension. 2019;73(5):926-935.

16. Madhur MS, et al. Hypertension: do inflammation and immunity hold the key to solving this epidemic? Circ Res. 2021;128(7):908-933.

17. Wenzel UO, et al. A pathogenic role of complement in arterial hypertension and hypertensive end organ damage. Am J Physiol Heart Circ Physiol. 2017;312(3):H349-H354.

18. Li J, et al. The role and mechanism of intestinal flora in blood pressure regulation and hypertension development. Antioxid Redox Signal. 2021;34(10):811-830.

19. Palmu J, et al. Association between the gut microbiota and blood pressure in a population 
cohort of 6953 individuals. JAm Heart Assoc. 2020;9(15):e016641.

20. Steinhelper ME, et al. Hypotension in transgenic mice expressing atrial natriuretic factor fusion genes. Hypertension. 1990;16(3):301-307.

21. Melo LG, et al. Chronic regulation of arterial blood pressure in ANP transgenic and knockout mice: role of cardiovascular sympathetic tone. Cardiovasc Res. 1999;43(2):437-444.

22. Reilly MP, et al. Increased formation of distinct F2 isoprostanes in hypercholesterolemia. Circulation. 1998;98(25):2822-2828.

23. Egan KM, et al. COX-2-derived prostacyclin confers atheroprotection on female mice. Science. 2004;306(5703):1954-1957.

24. Bayorh MA, et al. The role of oxidative stress in salt-induced hypertension. Am J Hypertens. 2004;17(1):31-36.

25. Dornas WC, et al. Oxidative stress causes hypertension and activation of nuclear factor $-\kappa \mathrm{B}$ after high-fructose and salt treatments. Sci Rep. 2017;7:46051.

26. von Geldern TW, et al. Atrial natriuretic peptide antagonists: biological evaluation and structural correlations. Mol Pharmacol.1990;38(6):771-778.

27. Park BM, et al. Attenuation of renovascular hypertension by cyclooxygenase-2 inhibitor partly through ANP release. Peptides. 2015;69:1-8.

28. Delporte C, et al. Discovery of a potent atrial natriuretic peptide antagonist for ANPA receptors in the human neuroblastoma NB-OK-1 cell line. Eur J Pharmacol. 1992;224(2-3):183-188.

29. Romero M, et al. Chronic treatment with atrial natriuretic peptide in spontaneously hypertensive rats: beneficial renal effects and sex differences. PLoS One. 2015;10(3):e0120362.

30. Grosser T, et al. The cardiovascular pharmacology of nonsteroidal anti-inflammatory drugs. Trends Pharmacol Sci. 2017;38(8):733-748.

31. Watanabe $\mathrm{H}$, et al. Effects of salt loading on blood pressure in mice lacking the prostanoid receptor gene. Circ J. 2005;69(1):124-126.

32. Francois $\mathrm{H}$, et al. Prostacyclin protects against elevated blood pressure and cardiac fibrosis.
Cell Metab. 2005;2(3):201-207.

33. Wang M, et al. Deletion of microsomal prostaglandin E synthase-1 augments prostacyclin and retards atherogenesis. Proc Natl Acad Sci US A. 2006;103(39):14507-14512.

34. Wang M, FitzGerald GA. Cardiovascular biology of microsomal prostaglandin E synthase-1. Trends Cardiovasc Med. 2010;20(6):189-195.

35. Jin Y, et al. Pharmacodynamic comparison of LY3023703, a novel microsomal prostaglandin e synthase 1 inhibitor, with celecoxib. Clin Pharmacol Ther. 2016;99(3):274-284.

36. Kennedy CR, et al. Salt-sensitive hypertension and reduced fertility in mice lacking the prostaglandin EP2 receptor. Nat Med.1999;5(2):217-220.

37. Harris RC, Breyer MD. Update on cyclooxygenase-2 inhibitors. Clin J Am Soc Nephrol. 2006;1(2):236-245.

38. Smolenski A. Novel roles of cAMP/cGMPdependent signaling in platelets. J Thromb Haemost. 2012;10(2):167-176.

39. John SW, et al. Genetic decreases in atrial natriuretic peptide and salt-sensitive hypertension. Science. 1995;267(5198):679-681.

40. Laskowski A, et al. Antioxidant actions contribute to the antihypertrophic effects of atrial natriuretic peptide in neonatal rat cardiomyocytes. Cardiovasc Res. 2006;72(1):112-123.

41. Pandey KN. Guanylyl cyclase/atrial natriuretic peptide receptor-A: role in the pathophysiology of cardiovascular regulation. Can J Physiol Pharmacol. 2011;89(8):557-573.

42. Ichiki T, et al. Atrial natriuretic peptide- old but new therapeutic in cardiovascular diseases. Circ J. 2017;81(7):913-919.

43. Mendelsohn ME. Protective effects of estrogen on the cardiovascular system. Am J Cardiol. 2002;89(12A):12E-17E.

44. Chang WC, et al. Effects of estradiol on the metabolism of arachidonic acid by aortas and platelets in rats. Biochim Biophys Acta. 1981;664(2):291-297.

45. Chang WC, et al. Stimulation of prostacyclin biosynthetic activity by estradiol in rat aortic smooth muscle cells in culture. Biochim Biophys
Acta. 1980;619(1):107-118.

46. Mikkola T, et al. 17 beta-estradiol stimulates prostacyclin, but not endothelin-1, production in human vascular endothelial cells. J Clin Endocrinol Metab. 1995;80(6):1832-1836.

47. Wilck N, et al. Salt-responsive gut commensal modulates $\mathrm{T}_{\mathrm{H}} 17$ axis and disease. Nature. 2017;551(7682):585-589.

48. Itani HA, et al. Activation of human T cells in hypertension: studies of humanized mice and hypertensive humans. Hypertension. 2016;68(1):123-132.

49. Amador CA, et al. Spironolactone decreases DOCA-salt-induced organ damage by blocking the activation of T helper 17 and the downregulation of regulatory T lymphocytes. Hypertension. 2014;63(4):797-803.

50. Madhur MS, et al. Interleukin 17 promotes angiotensin II-induced hypertension and vascular dysfunction. Hypertension. 2010;55(2):500-507.

51. Barhoumi T, et al. T regulatory lymphocytes prevent angiotensin II-induced hypertension and vascular injury. Hypertension. 2011;57(3):469-476.

52. Norlander AE, et al. Prostaglandin I 2 signaling licenses Treg suppressive function and prevents pathogenic reprogramming. J Clin Invest. 2021;131(7):e140690.

53. Miranda PM, et al. High salt diet exacerbates colitis in mice by decreasing Lactobacillus levels and butyrate production. Microbiome. 2018;6(1):57.

54. Zelante T, et al. Tryptophan catabolites from microbiota engage aryl hydrocarbon receptor and balance mucosal reactivity via interleukin-22. Immunity. 2013;39(2):372-385.

55. Cervantes-Barragan L, et al. Lactobacillus reuteri induces gut intraepithelial CD ${ }^{+} \mathrm{CD} 8 \alpha \alpha^{+} \mathrm{T}$ cells. Science. 2017;357(6353):806-810.

56. Rothhammer V, Quintana FJ. The aryl hydrocarbon receptor: an environmental sensor integrating immune responses in health and disease. Nat Rev Immunol. 2019;19(3):184-197.

57. Descamps HC, et al. The path toward using microbial metabolites as therapies. EBioMedicine. 2019;44:747-754. 